\title{
Catalytic microwave pyrolysis of waste engine oil using
} metallic pyrolysis char Su Shiung Lam ${ }^{\text {a,c,* }}$, Rock Keey Liew ${ }^{\text {a }}$, Chin Kui Cheng ${ }^{\text {b }}$, Howard A. Chase ${ }^{\mathrm{c}}$

${ }^{a}$ Eastern Corridor Renewable Energy Group (ECRE), School of Ocean Engineering, University Malaysia Terengganu, 21030 Kuala Terengganu, Terengganu, Malaysia ${ }^{b}$ Faculty of Chemical and Natural Resources Engineering, University Malaysia Pahang, Lebuhraya Tun Razak, 26300 Gambang, Kuantan, Pahang, Malaysia ${ }^{c}$ Department of Chemical Engineering and Biotechnology, University of Cambridge, New Museums Site, Pembroke Street, Cambridge CB2 3RA, United Kingdom 1am@umt.edu.my, lrklrk1991@gmail.com,chinkui@ump.edu.my, hac1000@cam.ac.uk * Corresponding author. Tel: +609 6683844; fax: +609 6683991; E-mail address: lam@umt.edu.my, sushiung@gmail.com (S.S. Lam); Postal address: Eastern Corridor Renewable Energy Group (ECRE), School of Ocean Engineering, University Malaysia Terengganu, 21030 Kuala Terengganu, Terengganu, Malaysia.

\section{Abstract}

6 Microwave pyrolysis was performed on waste engine oil pre-mixed with different amounts of metallic-char catalyst produced previously from a similar microwave pyrolysis process. The metallic-char catalyst was first prepared by pretreatment with calcination followed by analyses to determine its various properties. The heating characteristics of the mixture of waste oil and metallic-char during the pyrolysis were investigated, and the catalytic influence of the metallic-char on the yield and characteristics of the pyrolysis products are discussed 
22 with emphasis on the composition of oil and gaseous products. The metallic-char, detected to have a porous structure and high surface area $\left(124 \mathrm{~m}^{2} / \mathrm{g}\right)$, showed high thermal stability in a

$24 \mathrm{~N}_{2}$ atmosphere and it was also found to have phases of metals and metal oxides attached or adsorbed onto the char, representing a potentially suitable catalyst to be used in pyrolysis cracking process. The metallic-char initially acted as an adsorptive-support to adsorb metals, metal oxides and waste oil. Then, the char became a microwave absorbent that absorbed microwave energy and heated up to a high temperature in a short time and it was found to generate arcing and sparks during microwave pyrolysis of the waste oil, resulting in the formation of hot spots (high temperature sites with temperature up to $650{ }^{\circ} \mathrm{C}$ ) within the reactor under the influence of microwave heating. The presence of this high temperature metallic-char, the amounts of which are likely to increase when increasing amounts of metallic-char were added to the waste oil $(5,10$, and $20 \mathrm{wt} \%$ of the amount of waste oil added to the reactor), had provided a reducing chemical environment in which the metallicchar acted as an intermediate reductant to reduce the adsorbed metals or metal oxides into metallic states, which then functioned as a catalyst to provide more reaction sites that enhanced the cracking and heterogeneous reactions that occurred during the pyrolysis to convert the waste oil to produce higher yields of light hydrocarbons, $\mathrm{H}_{2}$ and $\mathrm{CO}$ gases in the pyrolysis products, recording a yield of up to $74 \mathrm{wt} \%$ of light $\mathrm{C}_{5}-\mathrm{C}_{10}$ hydrocarbons and 42 vol\% of $\mathrm{H}_{2}$ and $\mathrm{CO}$ gases. The catalytic microwave pyrolysis produced $65-85$ wt $\%$ yield of pyrolysis-oil containing $\mathrm{C}_{5}-\mathrm{C}_{20}$ hydrocarbons that can potentially be upgraded to produce transport-grade fuels. In addition, the recovered pyrolysis-gases (up to $33 \mathrm{wt} \%$ ) were dominated by aliphatic hydrocarbons (up to 78 vol\% of $\mathrm{C}_{1}-\mathrm{C}_{6}$ hydrocarbons) and significant amounts of valuable syngas (up to 42 vol\% of $\mathrm{H}_{2}$ and $\mathrm{CO}$ in total) with low heating values 45 (LHV) ranging from 4.7 to $5.5 \mathrm{MJ} / \mathrm{m}^{3}$, indicating that the pyrolysis-gases could also be used as a gaseous fuel or upgraded to produce more hydrogen as a second-generation fuel. The 
results indicate that the metallic-char shows advantages for use as a catalyst in microwave pyrolysis treatment of problematic waste oils.

\section{Keywords: pyrolysis; char; catalyst; waste; oil}

\section{Introduction}

Waste engine oil is an environmentally hazardous waste that is difficult to dispose of due to the presence of undesirable species such as soot and metals. On a global basis, nearly 24 million metric tons (Mt) of the waste oil are generated each year [1]. In particular, nearly 7.6 Mt are produced in the United States in addition to the approximately 2.2 Mt produced in the European Union [2]. Existing treatment processes such as incineration, combustion, and catalytic hydro-treatment are becoming increasingly impracticable due to concerns of environmental pollution and the difficulties of disposing of the sludge generated by these processes $[3,4]$.

Microwave pyrolysis has recently shown promise as an environmentally friendly disposal method for waste oil $[5,6]$. In this process, waste oil is mixed with a bed of highly microwave-absorbent material such as particulate-carbon in an inert atmosphere. As a result of microwave heating, the oil is thermally cracked into shorter hydrocarbon chains, producing hydrocarbon oils, gases, and char. The oil product can be catalytically upgraded to produce transport-grade fuels [7], and the gaseous product can be used as a source of chemical feedstock [5] or be reformed to produce hydrogen for use as a second-generation fuel [8]. The main processes occurring during microwave pyrolysis of waste oil have been described in previous works $[8,9]$ and can be summarized in Fig. 1. During the pyrolysis process, the waste oil ( $\approx \mathrm{C}_{40}$ hydrocarbons) is pyrolyzed through a primary pyrolysis stage in which the 
71 waste oil undergoes primary cracking and transforms into pyrolysis volatiles formed by a 72 mixture of hydrocarbon gases and liquid oils existing in a vapour phase. The pyrolysis

73 volatiles are generated from the primary cracking of waste oil that proceeds via a free-radical74 induced random scission mechanism as predicted by Rice's theory [10-12], consisting of 75 permanent gas species (e.g. $\left.\mathrm{H}_{2}, \mathrm{CO}, \mathrm{CO}_{2}\right)$, non-condensable gaseous hydrocarbons $\left(\mathrm{C}_{1}-\mathrm{C}_{4}\right.$ 76 hydrocarbons $)$, and condensable light hydrocarbons $\left(\approx \mathrm{C}_{25}\right.$ hydrocarbons). The pyrolysis 77 volatiles then undergo a secondary pyrolysis stage whereby serial and parallel secondary 78 reactions could occur and this results in the formation of products consisting of even ligther 79 condensable hydrocarbons $\left(\approx \mathrm{C}_{6}-\mathrm{C}_{18}\right.$ hydrocarbons collected as liquid hydrocarbon oil $)$ and 80 higher amounts of non-condensable gaseous hydrocarbons $\left(\mathrm{C}_{1}-\mathrm{C}_{4}\right.$ hydrocarbons $)$, and 81 permanent gas species (e.g. $\mathrm{H}_{2}, \mathrm{CO}, \mathrm{CO}_{2}$ ) in addition to the production of a char product. 82 Homogenous or heterogeneous secondary reactions could occur such as secondary cracking, 83 aromatization, reforming, deoxygenation, dehydrogenation, condensation, and carbonization 84 [8] (Fig. 1). 


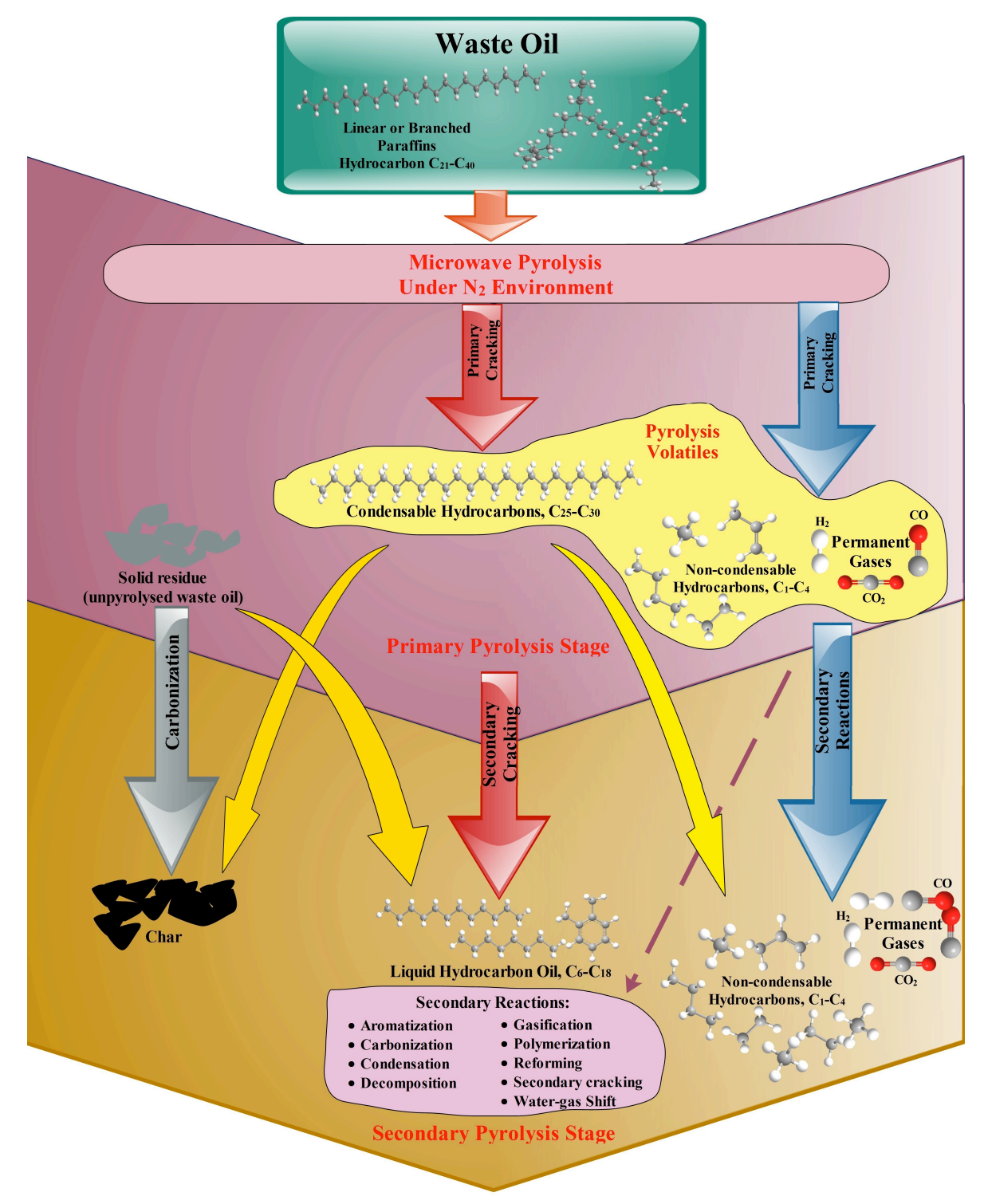

86 Fig. 1. Main processes occurring during microwave pyrolysis of waste oil: Primary pyrolysis consisting of primary cracking, and secondary pyrolysis consisting of serial and parallel secondary reactions occurring either homogeneously or heterogeneously.

The use of microwave radiation as a heat source is known to offer additional advantages over traditional thermal heat sources $[13,14]$, and the combination of carbon-based material and the novel use of microwave heating in pyrolysis processes is of increasing interest as reflected by considerable recent research reported in the literature [15-18]. Microwave

94 systems show a distinct advantage in providing a rapid, energy-efficient, and targeted heating process compared to conventional technologies, thus facilitating increased production rates and decreased production costs. Moreover, thermal energy is targeted only to microwave 
receptive materials and not to gases within the heating chamber or to the chamber itself. It can promote certain chemical reactions by selectively heating the reactants, leading to a more uniform temperature profile and improved yield of desirable products [16, 19].

100 The char produced is also a product of particular interest due to its potential use as a solid 101 fuel or as a catalyst in thermal cracking process. However, in order for the char products to be 102 put to these uses it must first be shown that they do not contain the toxic species originally present in waste oil; these species, particularly the undesired metals (e.g. $\mathrm{Cd}, \mathrm{Cr}$ ), are hazardous to human health and may not be emitted to the environment either in their current form or when converted to other substances as a result of their further use (e.g. combustion).

106 Metals derived from engine wear and oil additives are both toxic to humans and severely regulated in their disposal, preventing materials containing them to be disposed of via conventional routes (e.g. incineration) due to concerns over their potential dispersal to the environment.

110 It can also be inferred that if the microwave pyrolysis is to be performed in a continuous 111 operation over a long period of time, the amount of the char product trapped within the 112 particulate-carbon bed in the reactor would increase as a result of the prolonged period of 113 operation. The presence of increasing amounts of this char is likely to have an influence on 114 the product distribution in this pyrolysis process. This carbonaceous char, likely to contain 115 involatile metals originally present in waste oil, could act as a microwave-absorbent and heat 116 up by microwave radiation, and in turn pyrolyse the waste oil added into the reactor. It could 117 also promote certain heterogeneous reactions by heating the pyrolysis-volatiles evolved from 118 the pyrolysis of waste oil, leading to a different product composition observed in the 119 pyrolysis products. It has been reported that the metal-containing char product could 120 potentially be used as an inorganic catalyst in thermal cracking processes [20]; the presence 121 of some metals (e.g. Fe, Ni) in the char could have a catalytic effect on some of the 
122 heterogeneous reactions (e.g. methane decomposition reaction) that occurred as have been 123 reported by others in pyrolysis studies of other materials [19, 21, 22]. In addition, the use of

124 char produced from pyrolysis processes as a catalyst has recently shown advantages in

125 transforming biomass materials (e.g. sewage sludge, coffee hulls) into valuable gases such as

$126 \mathrm{H}_{2}$ and syngas in microwave pyrolysis process [16, 23-25]; the waste materials were mixed

127 with small amounts of the char and subjected to pyrolysis treatment.

128 In this study, microwave pyrolysis using a reactor bed of particulate-carbon was performed

129 on waste oil in the additional presence of different amounts of metallic-char produced 130 previously from the pyrolysis process as the catalyst in order to understand the influence of

131 the chemical nature and amount of the metallic-char on the yield of pyrolysis products and 132 with an emphasis on the chemical composition of the oil and gaseous products. The metallic133 char catalyst was pre-treated by calcination and characterized by different analytical methods

134 before and after being subjected to pyrolysis. In addition, a study was performed to examine 135 the heating characteristics of the mixture of waste oil and metallic-char in the presence of a 136 microwave-heated bed of particulate-carbon through monitoring its temperature profile 137 during the pyrolysis. These evaluations are important to examine if the metallic-char could 138 act as a microwave-absorbent and heat up by microwave radiation, and if the metallic-char 139 could be used as a catalyst in the pyrolysis of waste oil. Most existing waste oil pyrolysis 140 studies focus on conventional electric-resistance-heated and electric-arc-heated pyrolysis [26$14128]$, and there are very few studies about the pyrolysis products generated from microwave pyrolysis of waste oil, and in particular no similar studies have been reported on the

143 application of metallic-char as a catalyst in microwave pyrolysis of waste oil; this study aims 144 to rectify these deficiencies. 


\section{Experimental Section}

\subsection{Materials}

149 Shell 10W-40 motor oil was used throughout the experiments. The waste oil was sampled

150 from the crankcase of diesel engines run on unleaded fuel. Before pyrolysis, the oil samples

151 were filtered such that the size of any remaining particulates (i.e. metal particles, carbon soot,

152 and other impurities) was less than $100 \mu \mathrm{m}$. The oil samples were then examined for

153 hydrocarbon composition by Gas Chromatography-Mass Spectrometry (GC-MS), metal

154 composition by atomic-absorption spectrometry (AAS), phosphorus content by X-ray

155 Fluorescence (XRF) analyzer, and sulphur content by elemental analysis. The GC-MS

156 analysis (Table 1) revealed that the waste oil is formed from a mixture of low and high

157 molecular weight aliphatic and aromatic hydrocarbons, and the majority of the hydrocarbon

158 compounds were detected in the range of $\mathrm{C}_{7}-\mathrm{C}_{41}$. Phosphorus and sulphur were detected in

159 very low concentrations (phosphorus: $<0.1 \mathrm{wt} \%$; sulphur: $<0.8 \mathrm{wt} \%$ ); the sulphur content of

160 the waste oil has been reported and discussed in previous work [7]. The low concentrations of

161 sulphur and phosphorus could be explained by the removal of some oil additives containing

162 sulphur and phosphorus during the pre-filtration treatment of the waste oil, and also possibly

163 due to the transport of some additives into the vehicle exhaust system during engine operation

164 [29].

165 Table 1

166 Chemical composition (wt\%) of the waste oils.

\begin{tabular}{lr}
\hline Chemical composition & Waste oil \\
\hline Aliphatics & 91.3 \\
Alkanes & 90.4 \\
Naphthenes & 0.5 \\
Alkenes & 0.4 \\
Carbon components & \multicolumn{2}{c}{$\mathrm{C}_{7}-\mathrm{C}_{41}$} \\
\hline Aromatics & 1.2 \\
\hline Others $^{\text {a }}$ & 7.5 \\
\hline
\end{tabular}

${ }^{a}$ Unknown compounds due to unidentified peaks. 
169 Particulate-carbon (TIMREX FC250 Coke, TIMCAL Ltd, Bodio, Switzerland) with a 170 particle size ranging from $90-250 \mu \mathrm{m}$ was used as a microwave-absorbent to heat the waste

171 oil. The specifications of the carbon are presented in Table 2. The particulate-carbon was pre-

172 heated to $800^{\circ} \mathrm{C}$ for 50 minutes to remove any water and sulphur-containing compounds. The

173 sulphur content of the particulate-carbon was vaporized as sulphur-containing gases (e.g.

$174 \mathrm{H}_{2} \mathrm{~S}, \mathrm{SO}_{\mathrm{x}}$ ), which were then passed through a closed chamber filled with activated carbon that

175 acted as a sorbent to clean and retain sulphur from the gas streams. The pre-heated carbon

176 was then analyzed for its sulphur content by elemental analysis and that analysis showed that

177 the sulphur content had been reduced to $\leq 0.05 \mathrm{wt} \%$ after the heat treatment at $800{ }^{\circ} \mathrm{C}$.

178 Table 2

179 Characteristics of particulate carbon.

\begin{tabular}{lc}
\hline Parameter & Carbon (TIMREX FC250 Coke as provided by TIMCAL Ltd) \\
\hline Carbon & $99.91-99.10 \mathrm{wt} \%$ \\
Ash & $0.07-0.30 \mathrm{wt} \%$ \\
Moisture & $0.02-0.60 \mathrm{wt} \%$ \\
Sulphur & $1.3 \mathrm{wt} \%$ \\
Sieve size & $<250 \mu \mathrm{m}(2 \%>250 \mu \mathrm{m}, 75 \%>125 \mu \mathrm{m}, 85 \%>90 \mu \mathrm{m})$ \\
Density & $0.80-0.91 \mathrm{~g} / \mathrm{cm}^{3}$ \\
\hline
\end{tabular}

180

181

\subsubsection{Preparation of metallic-char as catalyst and its characterization}

182 Particles of metallic-char were obtained from the previous pyrolysis of waste oil at $550{ }^{\circ} \mathrm{C}$.

183 These chars with a particle size of $<30 \mu \mathrm{m}$ were separated from the particulate-carbon

184 particles $(90-250 \mu \mathrm{m}$ in size) that formed the bed that was used to conduct the pyrolysis

185 using sieves. Then, the char with a particle size ranging from $20-30 \mu \mathrm{m}$ was separated from

186 this previously sieved batch of chars $(<30 \mu \mathrm{m}$ in size $)$ using a narrow-range sieve, and used

187 for this study. The metallic-char was calcined at $600{ }^{\circ} \mathrm{C}$ in air atmosphere for $1 \mathrm{~h}$ and then

188 stored in a desiccator until further use as a catalyst. The preparation of the metallic-char for

189 use as a catalyst is briefly summarized in Fig. 2. The metallic-char was then examined for use

190 as a microwave-absorbent to heat the waste oil and also tested as a catalyst in the microwave

191 pyrolysis treatment of waste oil. 


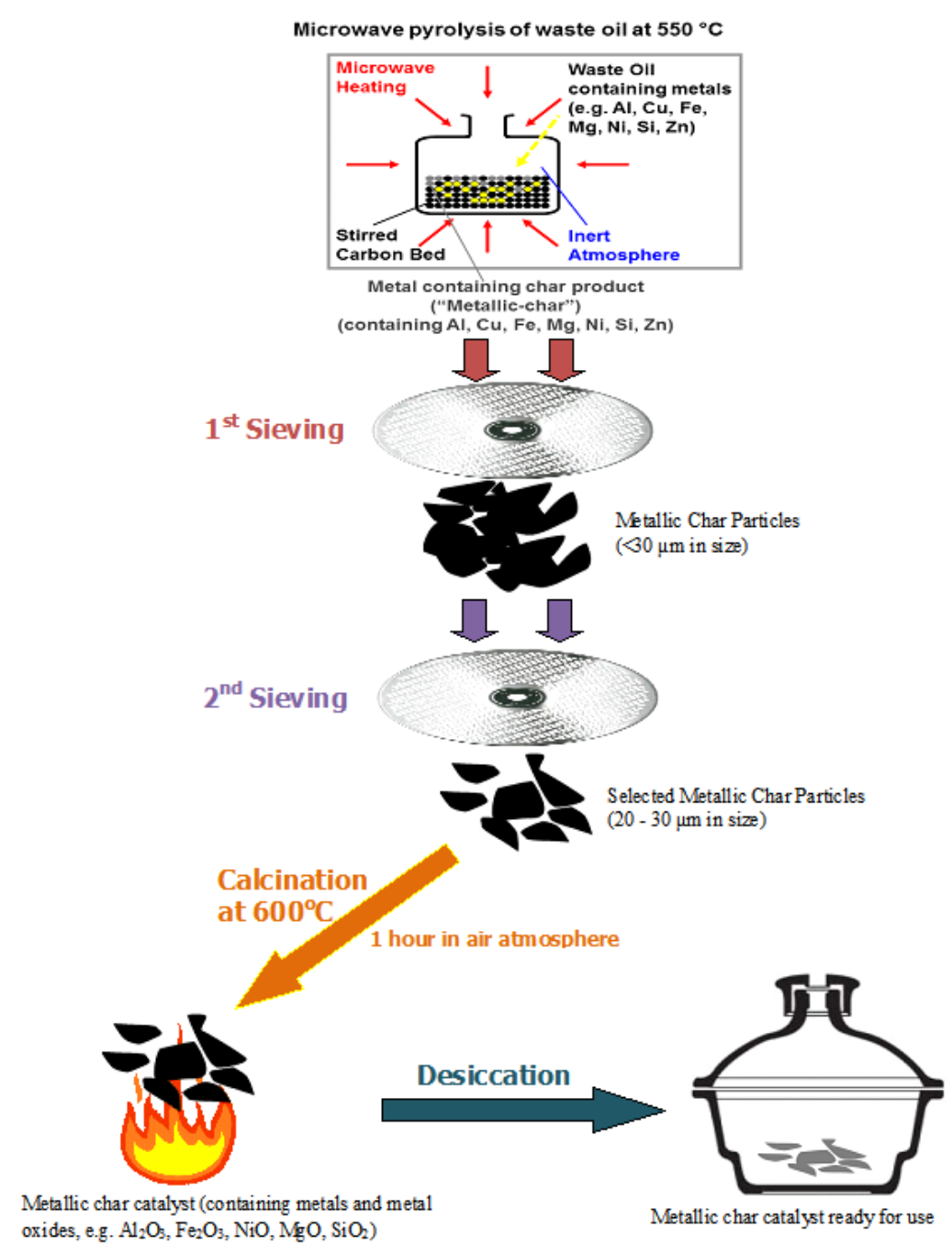

Fig. 2. Preparation of metallic pyrolysis char for use as a catalyst

195 The metallic-char catalyst before being subjected to pyrolysis was analyzed for its C, H, N,

$196 \mathrm{~S}$, and $\mathrm{O}$ content by elemental analysis, and its proximate composition by thermogravimetric 197 analysis (TGA). The remaining metallic-ash from TGA analysis was collected and analyzed 198 for its chemical composition by XRF, and its proximate composition was also analyzed by 199 TGA. Automatic sorption analysis (ASA) of the catalyst was performed to characterize its 200 porous structure and to determine its surface area and pore volume. The catalyst was also 201 analyzed by AAS to identify its metal composition.

202 X-ray diffraction (XRD) analyses using a X-Ray Diffractometer (Rigaku Corporation, Japan) were also performed on the catalyst before and after being subjected to pyrolysis to 
204 investigate its chemical composition. SEM/EDX was also performed on both the fresh and 205 used catalyst to investigate the size, morphology, presence of metals, and coke deposition on 206 the particles present in the catalyst. In addition, TGA was performed on the catalyst in an $\mathrm{N}_{2}$ 207 atmosphere to evaluate its thermal stability, whereas temperature programmed oxidation 208 (TPO) was performed on the used catalyst in an air atmosphere to investigate the reactivity of 209 the used catalyst with oxygen and also the oxidation of coked carbons deposited on the 210 surface of the used catalyst; these analyses were performd using a Q500 Thermogravimetric 211 Analyzer (TA Instruments UK Ltd, Crawley, West Sussex) in which the catalyst sample ( 20 $212 \mathrm{mg}$ ) was heated from ambient temperature to a final temperature at $950{ }^{\circ} \mathrm{C}$ at a heating rate of $21315^{\circ} \mathrm{C} / \mathrm{min}$ with a final holding time of $15 \mathrm{~min}$.

\subsection{Experimental details}

216 The experimental apparatus and method developed for this investigation have been 217 described in detail in previous work $[6,8]$. The only change from this description is the 218 addition of a Type-K metallic thermocouple to measure the evolution of the temperature of 219 the gases and pyrolysis-volatiles (evolved from the waste oil being pyrolyzed) present in the 220 vapor zone before they are driven out of the reactor into the product collection system by the

$221 \mathrm{~N}_{2}$ purge gas. The thermocouple enters the reaction chamber through a side port on the top of 222 the reactor and is positioned in the space above the carbon bed. In addition, a thermocouple 223 was used to monitor the temperature of the carbon load in the system; temperature 224 measurement in the reactor and its limitations are not the main focus of this paper and thus 225 are presented in Appendix A.

226 In outline, microwave pyrolysis was performed in a bell-shaped quartz reactor on waste oil 227 pre-mixed with small amounts of the metallic-char catalyst. The reactor was initially filled 228 with $1 \mathrm{~kg}$ of particulate-carbon as the reaction bed, which was then heated to $550{ }^{\circ} \mathrm{C}$ by 
229 microwave radiation (1). The particulate-carbon, added initially into the reactor in one batch, 230 was stirred (3) to ensure a uniform temperature distribution throughout the reactor and to 231 maximize heat transfer during pyrolysis. $\mathrm{N}_{2}$ purge-gas at a flow rate of $0.25 \mathrm{~L} / \mathrm{min}$ was 232 vented through the system to maintain the apparatus in an inert atmosphere. The microwave 233 generator was initially turned on to heat the carbon bed to the target pyrolysis temperature of $234550{ }^{\circ} \mathrm{C}$; the oven was then left for $5 \mathrm{~min}$ to ensure complete thermal equilibrium. The waste 235 oil was blended with different amounts of metallic-char $(5,10$, and $20 \mathrm{wt} \%$ of the amount of 236 waste oil added to the reactor, i.e. 5, 10, and $20 \mathrm{~g}$ of metallic-char/ $100 \mathrm{~g}$ of waste oil) to 237 create a waste oil-char mixture, which was then continuously added to the reactor (4) at a 238 constant feeding rate of $1 \mathrm{~kg} / \mathrm{h}$ when the temperature of the carbon bed had reached $550{ }^{\circ} \mathrm{C}$. 239 Products generated during pyrolysis, termed generally as pyrolysis volatiles (consisting of a 240 mixture of hydrocarbon gases, liquids, and suspended solids existing in a vapor phase), leave 241 the reactor and pass through a condensation system $(6,7,8,9)$. The heavier volatiles are 242 condensed into pyrolysis-oil $(10,11)$, and the lighter volatiles are collected as incondensable 243 pyrolysis-gases $(13,14)$, which can be sampled before being vented from the system. The 244 same procedure was repeated with the particulate-carbon as a control and all these results 245 were compared to the microwave pyrolysis experiments performed on waste oil in the 246 presence of only the particulate-carbon bed in the reactor. All the pyrolysis experiments were 247 performed under ambient atmospheric pressure.

248 The amount of additional residue material not converted to gaseous or liquid products (both 249 of which leave the reactor) was determined by measurement of the weight change in the 250 reactor and its contents before and after pyrolysis. The residue materials are likely to be chars 251 produced from tertiary cracking reactions of the pyrolysis process [5]. The char particles in 252 the reactor consisted of the char residues (i.e. the new char produced in this round of 253 pyrolysis, termed generally as "char product") together with the metallic-char catalyst added 
254 in combination with the waste oil into the reactor. These char particles mostly accumulated 255 on the surface of the carbon bed and they were separated from the particulate-carbon particles 256 (90 - 250 $\mu \mathrm{m}$ in size) using 90 and $250 \mu \mathrm{m}$ sieves. Then, the new char product, consisting of 257 char particles with the majority of particles present being $\leq 10 \mu \mathrm{m}$, was separated from the 258 original pyrolysis-char $(20-30 \mu \mathrm{m}$ in size $)$ using a $20 \mu \mathrm{m}$ sieve. It should be noted that the 259 new char product contained a relatively small amount of char particles larger than $10 \mu \mathrm{m}$ but 260 these larger char particles could not be analyzed due to the limitations involved in separating 261 them from the $20-30 \mu \mathrm{m}$ metallic-char that had been added in combination with the waste 262 oil into the reactor.

263 The yield of pyrolysis-oil was determined by measuring the weight increase in the 264 collecting vessels and filter. The gas yield was determined by mass balance and it was 265 assumed that whatever mass of added sample that was not accounted for by the pyrolysis-

266 char and pyrolysis-oil measurements left the system in gaseous form. All the pyrolysis 267 experiments were repeated for at least 5 times and the data recorded was the average of the 268 results obtained from three valid repeated runs performed under identical conditions and 269 excluded data from any experiments that were stopped due to equipment errors (e.g. 270 malfunctioning of stirrer, thermocouple, pump failure). These repeated experiments showed 271 good reproducibility and precision with low standard deviations shown in the product yields $272( \pm 1-5 \mathrm{wt} \%)$.

273 The waste oils, pyrolysis-oils, and pyrolysis-gases were examined for chemical 274 composition by different methods of gas chromatography analysis (i.e. GC-MS, GC-FID, and 275 GC-TCD); the detailed description of these analytical methods, e.g. the sample preparation, 276 the type of column used for the analysis, and the operating temperature program, have been 277 described in previous work $[7,8]$.

278 Studies were performed to measure the temperature versus time profile of the mixture of 
279 waste oil and metallic-char in the presence of a microwave-heated bed of particulate-carbon 280 as an indication of its heating characteristic during pyrolysis by microwave radiation. The 281 reactor was initially filled with $1 \mathrm{~kg}$ of particulate-carbon. The particulate-carbon was then 282 stirred and heated to $550{ }^{\circ} \mathrm{C}$ by microwave radiation, and the temperature profile was 283 monitored during the heating process. Waste oil pre-blended with metallic-char (i.e. a 80:20 284 wt\% mixture of waste oil and metallic-char) was continuously added to the reactor at a constant feeding rate of $1 \mathrm{~kg} / \mathrm{h}$ when the temperature of the carbon had reached $550{ }^{\circ} \mathrm{C}$. The temperature versus time profile of the mixture of particulate-carbon and waste oil-char 287 mixture continued to be monitored during the subsequently pyrolysis of the added waste oil288 char mixture.

\subsection{Analytical methods}

291 Oil samples were analyzed using a 6890/5973 GC-MS instrument (Agilent Technologies, 292 Palo Alto, CA), allowing the quantification of compounds by both species and size; the 293 detailed description of this analytical method has been reported in previous work [5, 7]. 294 Gases such as $\mathrm{H}_{2}, \mathrm{CH}_{4}, \mathrm{CO}, \mathrm{CO}_{2}$, were analyzed using a Varian 3380 gas chromatograph 295 (Varian Inc, Palo Alto, CA) fitted with two thermal conductivity detectors (GC-TCD), 296 whereas gaseous hydrocarbons from $C_{1}$ to $C_{4}$ were analyzed using a $6890 \mathrm{GC}$ (Agilent 297 Technologies, Palo Alto, CA) coupled with a flame ionization detector (GC-FID); the 298 detailed description of these analytical methods have been reported in previous work [8]. 299 Compounds were identified using the NIST 2005 mass spectral library using similarity 300 indices of $>70 \%$, or by comparison with published GC-MS data for similar products, and 301 quantification of compounds was obtained by external standard method and relative retention 302 times once the component has been identified.

303 Elemental analyses of solid samples were performed using a LECO CHNS-932 elemental 
analyzer (LECO Corporation, Michigan, USA); the detailed description of this analytical method is presented in Appendix B. TGA analysis of solid samples was performed using a Q500 Thermogravimetric Analyzer (TA Instruments UK Ltd, Crawley, West Sussex), allowing the proximate quantification of moisture, volatile matter, fixed carbon, and ash content of compounds. Detailed analysis (Appendix C) was performed according to ASTM Standard E1131-08 [30]. The oil and solid samples were also analyzed using a Varian Spectr AAS instrument; the detailed description of this analytical method, and the sample

311 preparation, has been reported in previous work [6]. Experimental analysis of each metal was 312 performed according to Lazaro et al. [31] and the standard working conditions specified in 313 the Varian AAS instruction manual for metal determination. The samples were analyzed for 314 their content of $\mathrm{Al}, \mathrm{As}, \mathrm{Ba}, \mathrm{Ca}, \mathrm{Cd}, \mathrm{Cu}, \mathrm{Cr}, \mathrm{Fe}, \mathrm{Mg}, \mathrm{Mo}, \mathrm{Ni}, \mathrm{Pb}, \mathrm{Si}, \mathrm{V}$ and $\mathrm{Zn}$.

315 ASA analysis of the solid samples was performed using a Micromeritics ASAP 2010 316 Automatic Sorption Analyzer (Micromeritics UK Ltd, Dunstable, Bedfordshire) to 317 characterize their porous structure and to determine their surface area. $90 \mathrm{mg}$ of sample was 318 degassed at $120{ }^{\circ} \mathrm{C}$ for $2 \mathrm{~h}$ prior to analysis. Then, the sample was exposed to varying 319 pressures of $\mathrm{N}_{2}$ gas at a temperature of $77 \mathrm{~K}$, and the volume of $\mathrm{N}_{2}$ adsorbed onto the sample's surface at different pressures was recorded. The data were used to plot the $\mathrm{N}_{2}$

321 adsorption and desorption isotherms that allow the characterization of porous structure and 322 calculation of surface area of the sample using the Multipoint Brunauer, Emmett, and Teller 323 (BET) equation [32, 33]. External surface area and micropore volume were calculated based 324 on the $t$-plot method, and the total pore volume was determined at $\mathrm{P} / \mathrm{P}_{0}$ of 0.99 .

\section{Results and Discussion}

327 Microwave pyrolysis of waste oil was performed in order to convert the waste oil into potentially valuable products suitable for use as a fuel. The pyrolysis was performed in a 
329 continuous operation using the apparatus described, which is fitted with magnetrons capable

330 of delivering $5 \mathrm{~kW}$ of microwave power and capable of sustaining a waste oil feed rate of 5

$331 \mathrm{~kg} / \mathrm{h}$ with a positive energy ratio of 11 (energy content of hydrocarbon products/ electrical 332 energy supplied for microwave heating) and a net energy output of $170 \mathrm{MJ} / \mathrm{h}$.

333 Table 3

334 Characteristics of the metallic-char and metallic-ash.

\begin{tabular}{lcc}
\hline & Metallic-char $^{\text {a }}$ & Metallic-ash $^{\text {b }}$ \\
\hline Elemental composition (wt\%) & & \\
C & 86.3 & n.p. \\
H & 4 & n.p. \\
N & 0.2 & n.p. \\
S & 0.5 & n.p. \\
O & 9 & n.p.
\end{tabular}

Proximate composition (wt $\%$ )

Moisture

Volatile matter

$-d$

Fixed carbon

5

Ash

85

Particle size

10

Surface area

External surface area $\left(\mathrm{m}^{2} / \mathrm{g}\right)$

Micropore area $\left(\mathrm{m}^{2} / \mathrm{g}\right)$ $20-30 \mu \mathrm{m}$

$124 \mathrm{~m}^{2} / \mathrm{g}$

28

97

Micropore volume $\left(\mathrm{cm}^{3} / \mathrm{g}\right)$

0.065

Total pore volume $\left(\mathrm{cm}^{3} / \mathrm{g}\right)$

0.13

Metal composition of metallic-char (ppm)

Al

$\mathrm{Ca}$

6.1

910

$\mathrm{Mg}$

229

$\mathrm{Cd}$

0.3

$\mathrm{Ni}$

4.3

$\mathrm{Cu}$

1.6

$\mathrm{Pb}$

1.2

$\mathrm{Fe}$

42.8

$\mathrm{Si}$

23.6

$\mathrm{Zn}$

488

Chemical composition of metallic-ash by XRF analysis ( $\mathrm{wt} \%$ )

$\begin{array}{lclc}\mathrm{SiO}_{2} & 5.2 & \mathrm{MgO} & 15.1 \\ \mathrm{Al}_{2} \mathrm{O}_{3} & 4.3 & \mathrm{ZnO} & 16.7 \\ \mathrm{Fe}_{2} \mathrm{O}_{3} & 7.3 & \mathrm{CuO} & 1.1 \\ \mathrm{CaO} & 21.0 & \mathrm{NiO} & 3.2 \\ \mathrm{~K}_{2} \mathrm{O} & 0.3 & \mathrm{PbO} & 0.3 \\ \mathrm{Na}_{2} \mathrm{O} & 0.5 & & \end{array}$

${ }^{\mathrm{a}}$ Obtained from microwave pyrolysis of waste oil at $550^{\circ} \mathrm{C}$ followed by calcination at $600{ }^{\circ} \mathrm{C}$ 336 in air atmosphere for $1 \mathrm{~h}$.

$337{ }^{\mathrm{b}}$ Ash collected from heating the metallic-char at $950{ }^{\circ} \mathrm{C}$ in air atmosphere for $20 \mathrm{~min}$.

$338{ }^{c}$ n.p.- Analysis not performed.

$339{ }^{\mathrm{d}}$ Not detectable. 


\subsection{Charateristics of metallic-char catalyst}

342 The metallic-char was analyzed to determine its elemental, proximate, and metal

343 composition, and also its surface area, external surface area, micropore area, micropore

344 volume, and total pore volume. In addition, the metallic-ash was collected from heating the

345 metallic-char at $950{ }^{\circ} \mathrm{C}$ in air atmosphere for $20 \mathrm{~min}$ and the ash was analyzed for its

346 chemical composition. Table 3 summarizes the main characteristics of the metallic-char and

347 metallic-ash.

348 The results from elemental analysis show that carbon $(\sim 86 \mathrm{wt} \%)$ and oxygen $(9 \mathrm{wt} \%)$

349 represented the main elements present in the metallic-char, whereas hydrogen (4 wt $\%$ ),

350 nitrogen $(0.2 \mathrm{wt} \%)$, and sulphur $(0.5 \mathrm{wt} \%)$ were detected in very low concentrations. The

351 detection of oxygen in the metallic-char indicates that char oxidation had occurred to some

352 extent to form possibly metal oxides during the preparation of the metallic-char for use as a

353 catalyst by calcination the char at $600^{\circ} \mathrm{C}$ in air for $1 \mathrm{~h}$ (See Section 2.1.1, Fig. 2).

354 Proximate analysis revealed that the metallic-char comprised mainly of fixed carbon (85 $\mathrm{wt} \%)$ and smaller amounts of ash $(10 \mathrm{wt} \%)$ and volatile matter (5 wt $\%)$, whereas moisture was not detected in the metallic-char. The high content of carbon (also detected from elemental analysis) and the relatively low content of volatile matter show that a carbonaceous

358 char with a high elemental carbon content was obtained from the previous pyrolysis of waste oil at $550{ }^{\circ} \mathrm{C}$. The ash is likely to derive from the metals originally present in the waste oil

360 [6], which were then transferred and either adsorbed onto or trapped within the metallic-char 361 during the previous pyrolysis of waste oil.

362 The metallic-ash was further analyzed and examined for its chemical composition by 363 proximate and XRF analysis. As expected, ash represented the main elements (94 wt\%) 364 present in the metallic-ash as demonstrated by proximate analysis, whereas volatile matter 365 and fixed carbon were detected in very low concentrations ( $2 \mathrm{wt} \%$ and $4 \mathrm{wt} \%$, respectively). 
366 XRF analysis revealed that the metallic-char contained metal oxides comprising mainly of $367 \mathrm{CaO}, \mathrm{ZnO}, \mathrm{MgO}, \mathrm{Fe}_{2} \mathrm{O}_{3}, \mathrm{SiO}_{2}, \mathrm{Al}_{2} \mathrm{O}_{3}$, and $\mathrm{NiO}$. The detection of these metal oxides suggests 368 that some of the metals originally attached or adsorbed onto the metallic-char were likely to 369 have reacted with oxygen to form metal oxides that were retained within the metallic-char 370 during the preparation of the metallic-char as a catalyst by calcination.

371 The results from AAS showed that the metallic-char also contained metals such as $\mathrm{Ca}, \mathrm{Zn}$, $372 \mathrm{Mg}, \mathrm{Fe}, \mathrm{Si}, \mathrm{Al}$, and $\mathrm{Ni}$; this supports the proposed occurrence of char oxidation that had led to 373 the formation of metal oxides during the calcination of the metallic-ash. These metals were 374 originally derived from the involatile metals attached or adsorbed onto the metallic-char 375 during the previous pyrolysis of waste oil. The involatile metals were derived from the wear and corrosion of the iron and alloy engine components or additives present in the engine oil

377 [6]. The concentrations of $\mathrm{Ca}, \mathrm{Fe}, \mathrm{Mg}, \mathrm{Si}$ and $\mathrm{Zn}$ in the metallic-char were found to be 378 relatively high compared to the amounts of other metals present. In contrast, $\mathrm{Cu}, \mathrm{Cd}$, and $\mathrm{Pb}$ 379 were detected in low concentrations ( $<1.6 \mathrm{ppm})$. Some of these metals such as $\mathrm{Fe}, \mathrm{Ni}, \mathrm{Si}, \mathrm{Al}$ 380 may have catalytic effects on the reaction pathways that occur in this pyrolysis process as reported by others in pyrolysis studies of other materials [34-36] and this could lead to a different product composition compared to that observed in previous works [7, 8].

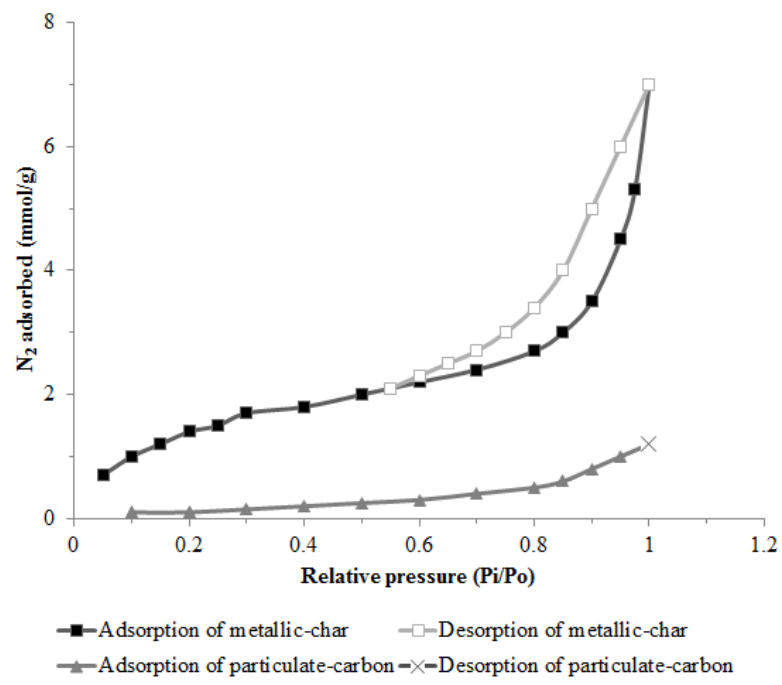

Fig. 3. $\mathrm{N}_{2}$ adsorption and desorption isotherms of metallic-char and particulate-carbon 
Fig. 3 shows the $\mathrm{N}_{2}$ adsorption and desorption isotherms plotted from the volume of $\mathrm{N}_{2}$ adsorbed onto the surface of metallic-char and particulate-carbon at different pressures of $\mathrm{N}_{2}$ gas. The adsorption-desorption isotherm obtained for the metallic-char indicates a combination between the isotherms of Type I and Type IV according to the classification of adsorption isotherms by International Union of Pure and Applied Chemistry (IUPAC) and 390 Brunauer, Deming, Deming, and Teller (BDDT system) [37]. The plot at lower relative pressures $(\mathrm{Pi} / \mathrm{Po} \leq 0.5)$ shows a Type $\mathrm{I}$ adsorption isotherm indicative of a microporous structure whereas the plot at higher relative pressures $(\mathrm{Pi} / \mathrm{Po}>0.5)$ indicates a Type IV adsorption isotherm in which capillary or pore condensation occurred and this generated a hysteresis loop indicating the presence of mesoporosity. These observations suggest that the metallic-char had both microporous and mesoporous structure; porous solid is classified as microporous with a pore size of up to $2 \mathrm{~nm}$ and mesoporous with a pore size of $2-50 \mathrm{~nm}$ by 397 IUPAC.

398 The metallic-char showed a type H1 hysteresis loop according to the classification of hysteresis loops by IUPAC as indicated by adsorption and desorption branches that are nearly 400 vertical and parallel, indicating the presence of a porous structure containing relatively 401 uniform cylindrical pores with a narrow distribution of pore size. The presence of type H1 hysteresis loop is also indicative of both delayed condensation and little hold-up of 403 percolation, showing a characteristic of good adsorption capacity by the metallic-char, 404 particularly for adsorbing metal ions [38]. The data from the $\mathrm{N}_{2}$ adsorption and desorption 405 isotherms were calculated for determination of the surface area and the metallic-char was 406 found to have a surface area of $124 \mathrm{~m}^{2} / \mathrm{g}$, the majority of which was comprised of micropores $407\left(97 \mathrm{~m}^{2} / \mathrm{g}\right)$, and a micropore volume of $0.065 \mathrm{~cm}^{3} / \mathrm{g}$, indicating that this char had a relatively 408 high internal porosity (Table 3 ). These results support the highly porous structure with many 409 cavities observed in the SEM/EDX scans of the metallic-char (Fig. 4). 
410 In contrast, the particulate-carbon that was used as a microwave-absorbent in this study

411 showed a plot of a convex curve to the relative pressure axis and with no sign of hysteresis

412 loop (Fig. 3), indicating a Type III adsorption isotherm. The presence of Type III adsorption

413 isotherm is commonly associated with characteristics of non-porous structure, low surface

414 area, pore volume, weak adsorbate-adsorbent interactions, and low adsorption capacity [38].

415 The different adsorption isotherm observed between the metallic-char and particulate-carbon

416 indicated that the metallic-char showed a higher adsorption capacity compared to the

417 particulate-carbon, suggesting that the metallic-char could be a more suitable adsorptive-

418 support to adsorb metal ions and waste oil (or the evolved pyrolysis-volatiles) in order for

419 catalytic heterogeneous reactions to occur during the use of the metallic-char as a catalyst in

420 the microwave pyrolysis conversion of the waste oil.

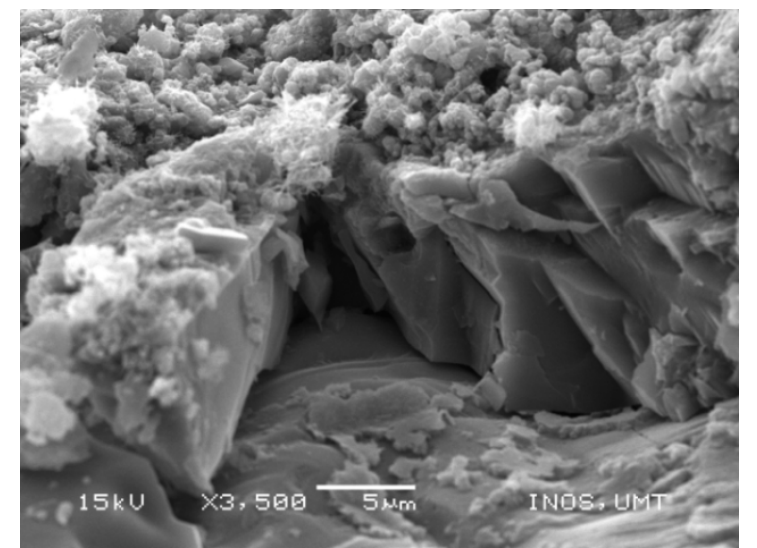

SEM of fresh metallic-char

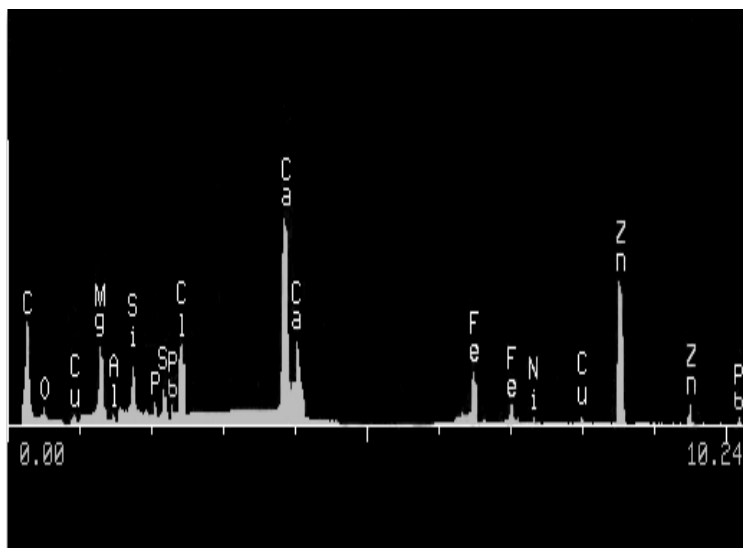

EDX of fresh metallic-char

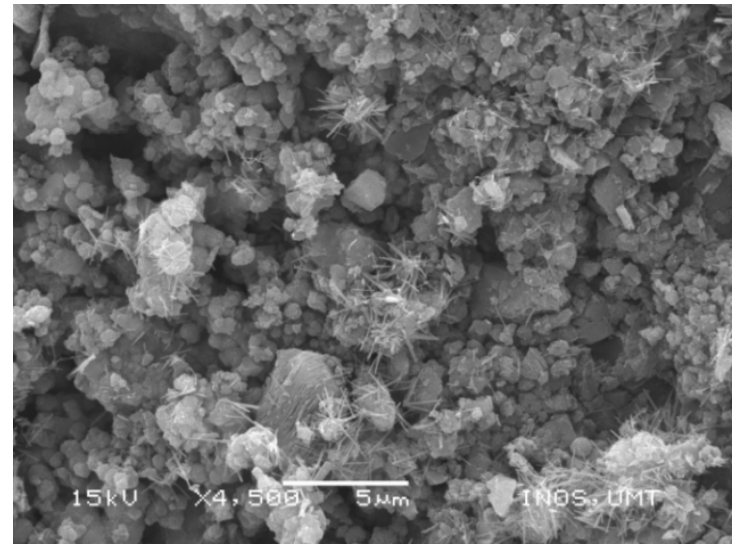

SEM of used metallic-char

Fig. 4. SEM micrograph and EDX spectrum of particulate matter in the metallic-char before and after pyrolysis. These highly magnified scans show example areas of the samples; numerous areas were scanned and examined for consistency. 
426 Fig. 4 presents the SEM-micrograph and EDX-spectrum of the fresh metallic-char. The

427 SEM/EDX scans demonstrated that the metallic-char had a porous structure nearly 428 comparable to activated char with most of the particles having a nearly spherical shape. The 429 presence of highly porous structure indicates that the metallic-char can be a suitable 430 candidate for use as a catalyst support or adsorbent as has been reported by Y. Shen et al. 431 [38]. Cavities and particles having a particle size of about $1-5 \mu \mathrm{m}$ were found distributed 432 over the metallic-char, indicating the presence of a porous network with a high surface area. 433 The small particles were likely to be formed by smaller char and metallic particles either 434 attached or adsorbed onto the metallic-char.

435 The EDX spectrum of the metallic-char (Fig. 4) showed the presence of metalloid (Si), non-metals $(\mathrm{C}, \mathrm{O}, \mathrm{P}, \mathrm{S})$, halogen $(\mathrm{Cl})$, and metals $(\mathrm{Cu}, \mathrm{Mg}, \mathrm{Al}, \mathrm{Ca}, \mathrm{Fe}, \mathrm{Ni}, \mathrm{Zn}, \mathrm{Pb})$. Some of 437 these metal elements $(\mathrm{Cu}, \mathrm{Al}, \mathrm{Mg}, \mathrm{Fe}, \mathrm{Ni})$ have been reported to show catalytic effect on the 438 heterogeneous reactions that occurred in pyrolysis process $[19,21,22]$; this further indicates 439 the potential of the metallic-char to be used as a catalyst.

440 The SEM-micrograph of the used metallic-char is also presented in Fig. 4. As shown in

441 Fig. 4, the used metallic-char was covered with a layer consisting of small particles of 442 different sizes. The layer of small particles were likely to be coked carbons produced during 443 the pyrolysis process. In addition, some of the small particles could be the metal particles 444 formed from the reduction of metal oxides originally present in the metallic-char (Table 3).

\subsubsection{XRD analysis of metallic-char before and after pyrolysis}

447 The metallic-char was analyzed by XRD to investigate the presence and change of 448 crystalline phases on the metallic-char structure before and after pyrolysis. Fig. 5 shows the 449 XRD plots of the fresh and used metallic-char from microwave pyrolysis expeirments 
450 performed on waste oil. The XRD of the fresh metallic-char showed the presence of metal 451 phases containing $\mathrm{Al}, \mathrm{Ca}, \mathrm{Fe}, \mathrm{Mg}, \mathrm{Ni}, \mathrm{Si}$, and $\mathrm{Zn}$, and also phases of metal oxides comprising $452 \mathrm{SiO}_{2}, \mathrm{Al}_{2} \mathrm{O}_{3}, \mathrm{Fe}_{2} \mathrm{O}_{3}, \mathrm{CaO}, \mathrm{MgO}, \mathrm{ZnO}$, and $\mathrm{NiO}$. Although other metals (e.g. $\mathrm{Cd}, \mathrm{Cu}, \mathrm{Pb}$ ) and 453 metal oxides (e.g. $\mathrm{K}_{2} \mathrm{O}, \mathrm{Na}_{2} \mathrm{O}, \mathrm{CuO}, \mathrm{PbO}$ ) were detected in the metallic-char by $\mathrm{XRF}$ and 454 AAS analyses, their peaks were not detectable by XRF analysis, probably due to their low 455 concentrations in the metallic-char (Table 3).

456 For used metallic-char, lower peaks were observed for the metal oxides and relatively 457 higher peaks identified as $\mathrm{Al}, \mathrm{Fe}, \mathrm{Mg}, \mathrm{Zn}$, and $\mathrm{Ni}$ phase were detected compared to those 458 observed in the fresh metallic-char (Fig. 5). This suggests that some of the metal oxides 459 (originally attached to the metallic-char) had been reduced to form their metal elements 460 through the reductive and heterogeneous reactions (e.g. steam reforming) that occurred 461 between the waste oil (or the evolved pyrolysis-volatiles) and the carbon and metal oxides in 462 the metallic-char during the pyrolysis at a high temperature of $550{ }^{\circ} \mathrm{C}$. It was likely that the 463 metallic-char, being a carbonaceous material that can be heated and transformed into a high 464 temperature site under the influence of microwave heating, had provided a reducing chemical 465 environment in which the metallic-char acted as an intermediate reductant to reduce the 466 adsorbed metal oxides into its metallic states (R10, R11; see Section 3.4.2). In addition, 467 sintering of metal particles such as $\mathrm{Ni}$ could occur as a result of the high temperature 468 provided under the microwave pyrolysis condition [39]. 


\section{Fresh metallic-char}

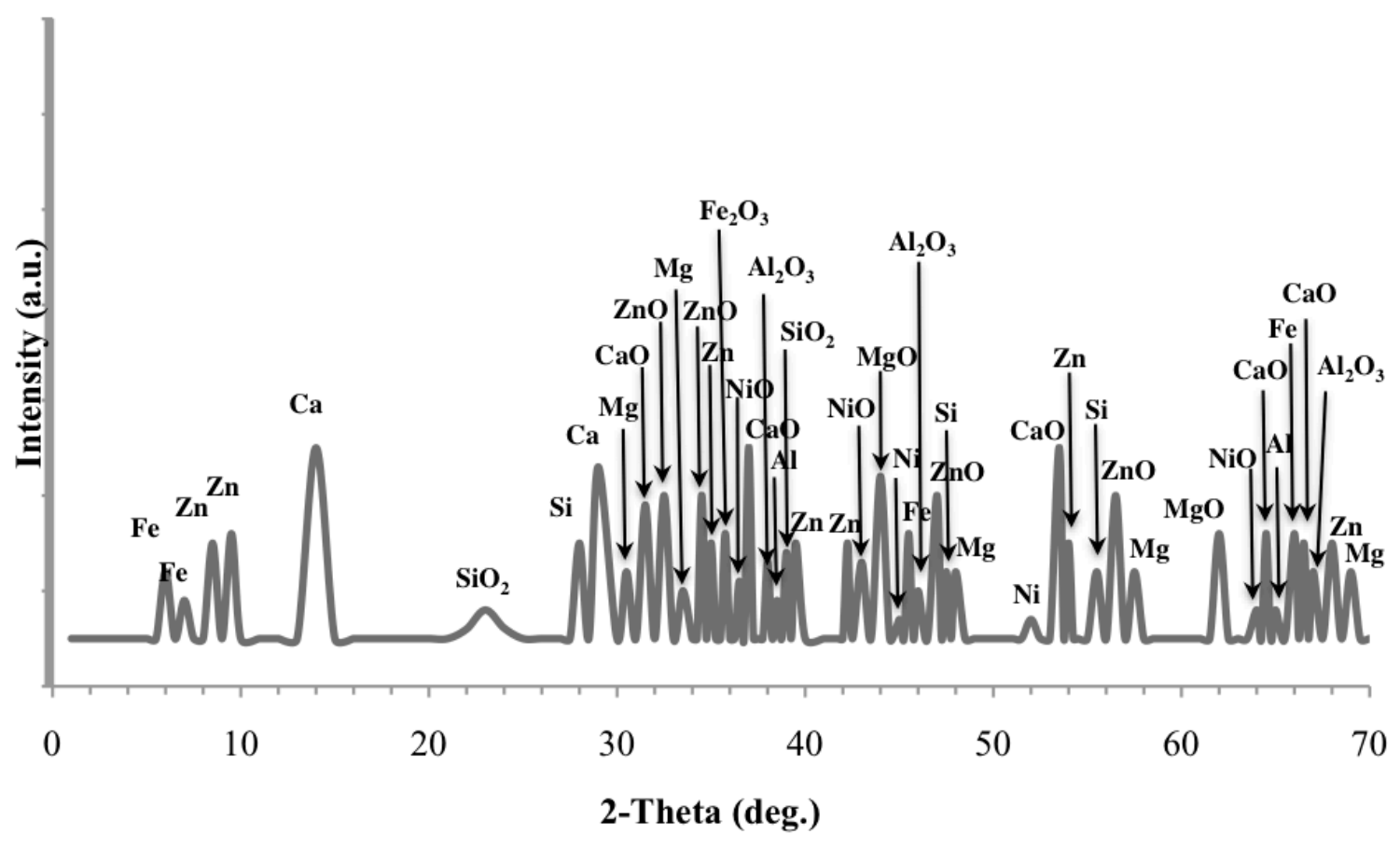

Used metallic-char

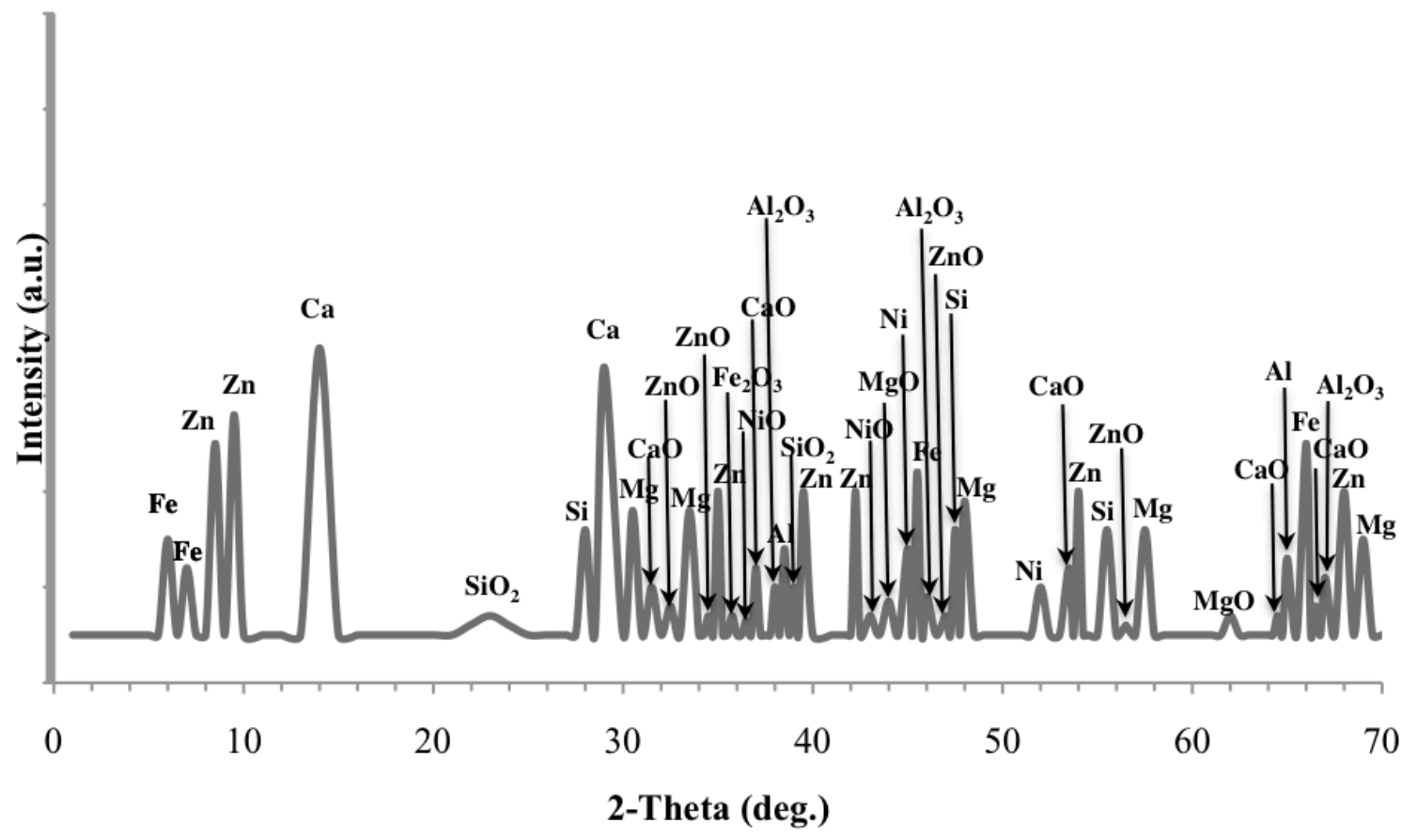

Fig. 5. XRD analysis of fresh and used metallic-char 


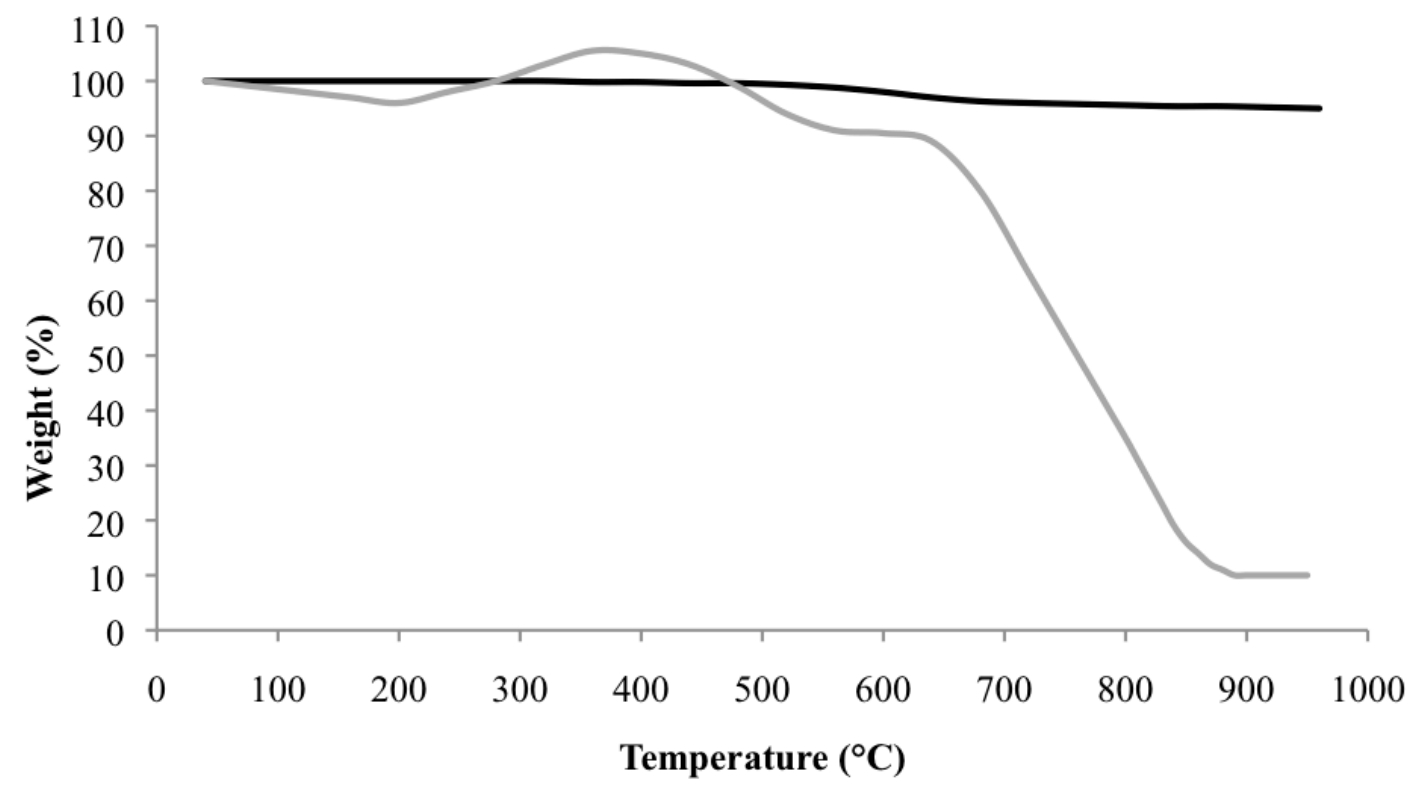

- TGA curve of fresh metallic-char in nitrogen atmosphere

— TPO curve of used metallic-char in air atmosphere

Fig. 6. TGA and TPO analysis of metallic-char

\section{3.1.3. TGA and TPO analysis of metallic-char before and after pyrolysis}

475 The metallic-char before pyrolysis was analyzed by TGA as an evaluation of its thermal

476 stability under pyrolysis environment in an $\mathrm{N}_{2}$ atmosphere, and the resulting plot is presented

477 in Fig. 6. It was revealed that the metallic-char showed high thermal stability in a $\mathrm{N}_{2}$ 478 atmosphere as indicated by only a small reduction in weight $(5 \%)$ with the increase of 479 temperature up to $900{ }^{\circ} \mathrm{C}$. This indicates that the metallic-char is durable to be used in a pyrolysis conversion process due to its high thermal stability under pyrolysis environment in

481 an $\mathrm{N}_{2}$ atmosphere.

482 The used metallic-char was analyzed by TPO to investigate its reactivity with oxygen in an 483 air atmosphere and also the oxidation of coked carbons deposited on the surface of the used catalyst. The TPO curve of the used metallic-char under air atmosphere is demonstrated in

485 Fig. 6. The weight of the used metallic-char was found to decrease about $4 \%$ initially when it 486 was heated to about $200{ }^{\circ} \mathrm{C}$, which was likely due to the evaporation of water present in the 
487 char. The weight of the char then increased slightly for about $9 \%$ from $200-400{ }^{\circ} \mathrm{C}$, which 488 could possibly be attributed to the oxidation of metallic elements present in the used char (see 489 Fig. 5 for the metallics phase observed in the used metallic-char from XRD analysis), e.g. 490 oxidation of metallic $\mathrm{Ni}$ as has been reported by $\mathrm{Wu}$ and Williams [40]. After $400{ }^{\circ} \mathrm{C}$, the 491 used metallic-char showed a reduction in weight for about $13 \%$ when it was heated to $560{ }^{\circ} \mathrm{C}$, 492 and the weight remained at about $90 \%$ until $600{ }^{\circ} \mathrm{C}$. The reduction in weight between $400{ }^{\circ} \mathrm{C}$ 493 and $600{ }^{\circ} \mathrm{C}$ could be explained by the oxidation of the coke carbons deposited on the used 494 metallic-char. This result is in agreement with the findings of other workers in which the 495 authors have reported that the oxidation or combustion of carbon deposited on the surface of 496 a catalyst normally happens at temperatures between 400 and $600{ }^{\circ} \mathrm{C}[34,35]$. The metallic497 char then showed a dramatic reduction of about $80 \%$ of weight when it was heated from 600 $900{ }^{\circ} \mathrm{C}$ in air, and the weight remained at $10 \%$ throught the remaining heating period. The 499 dramatic reduction of weight at this temperature range suggests that the fixed carbon 500 originally present in the metallic-char (Table 3) was likely to have reacted with the oxygen 501 present in the air to form carbon oxides at temperature above $600{ }^{\circ} \mathrm{C}$. It can also be inferred from these results that a temperature of $600{ }^{\circ} \mathrm{C}$ can be selected for thermal regeneration of the metallic-char in order to extend its service life since this temperature represents the optimum

504 balance between sufficiently high temperature needed to remove the coked carbon deposited 505 on the used metallic-char, while not being so high as to promoting the oxidation of the fixed 506 carbon in the metallic-char that would result in weight reduction of the char. 


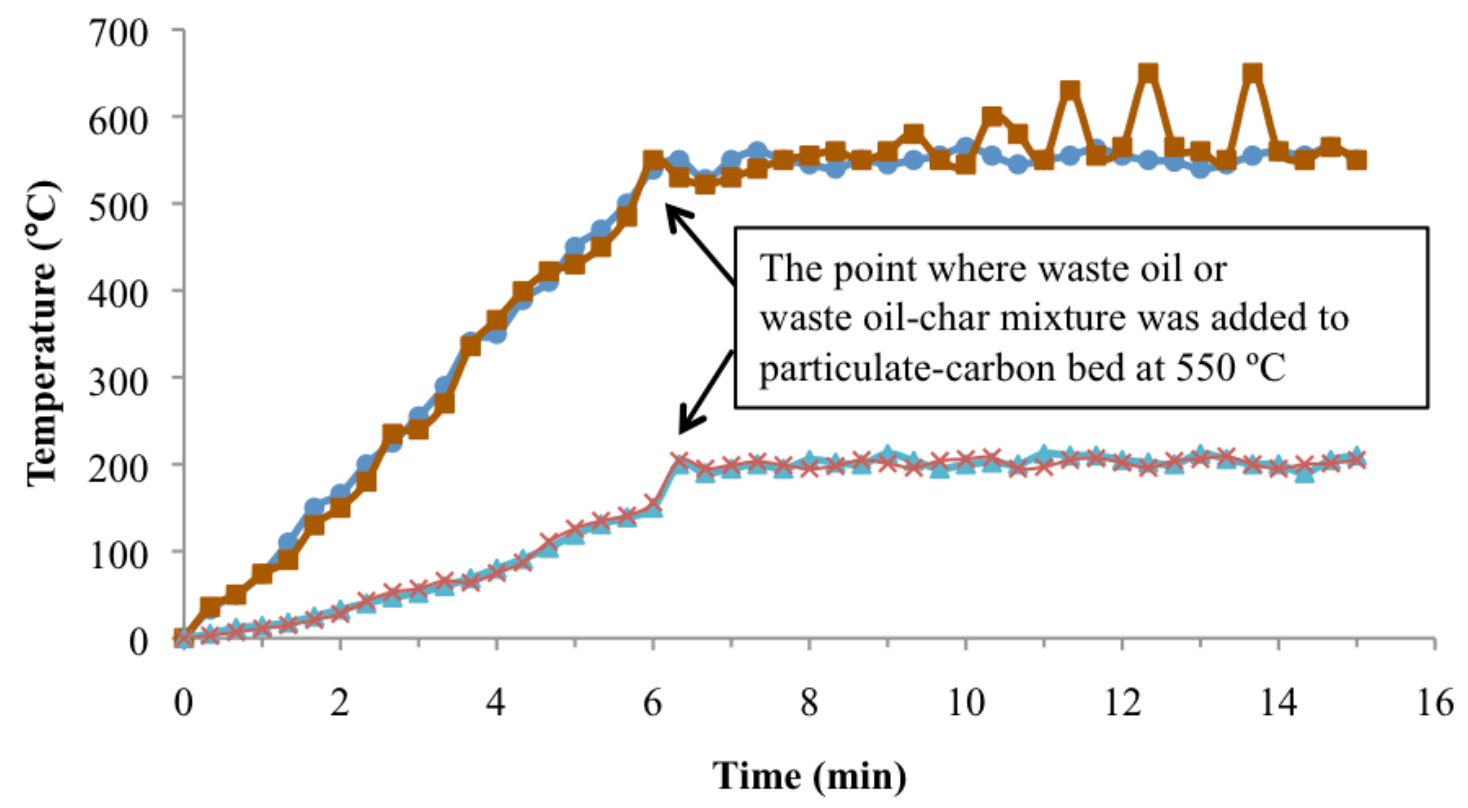

$\multimap$ Particulate-carbon bed (waste oil added at $550{ }^{\circ} \mathrm{C}$ )

$\rightarrow$ Particulate-carbon bed (waste oil pre-mixed with metallic-char added at $550^{\circ} \mathrm{C}$ )

- Vapour zone (waste oil added at $550{ }^{\circ} \mathrm{C}$ )

$*$ Vapour zone (waste oil pre-mixed with metallic-char added at $550{ }^{\circ} \mathrm{C}$ )

513 Fig. 7. Temperature profiles during microwave pyrolysis of waste oil by contact with a bed of 514 particulate-carbon $(1 \mathrm{~kg})$ in the additional presence of a small amount of metallic-char pre515 added to the waste oil ( $20 \mathrm{wt} \%$ of the amount of waste oil added to the reactor). The data 516 presented show typical results for the temperature profile obtained in experiments with low 517 standard deviations shown in the temperature reading $\left( \pm 1-6^{\circ} \mathrm{C}\right)$ for each reference point.

519 3.2. Temperature profile of the mixture of waste oil and metallic-char during the pyrolysis by microwave radiation

521 Fig. 7 shows the temperature profile of the mixture of waste oil and metallic-char after 522 addition to a bed of particulate-carbon during the pyrolysis by microwave radiation. The 523 temperature profiles shown in Fig. 7 are limited to the particular configuration of the 524 microwave pyrolysis system used in the experimental apparatus developed for this 525 investigation.

526 The waste oil-char mixture (80:20 wt $\%)$ was continuously added to the reactor containing a 527 bed of particulate-carbon maintained at the target temperature of $550{ }^{\circ} \mathrm{C}$ by microwave 528 heating. This initiated the pyrolysis process and the waste oil was pyrolyzed and transformed 
529 into pyrolysis-volatiles, which then left the reactor and passed through the product collection 530 system. Electrical arcing was found to occur and sparks were observed 3 minutes after the 531 initial injection of the waste oil-char mixture into the hot carbon bed. Such a phenomenon 532 was found to occur intermittently within and on the surface of the carbon bed and this 533 resulted in a series of transient rises of temperature readings to a maximum of $650{ }^{\circ} \mathrm{C}$ during 534 the pyrolysis of the waste oil-char mixture. Nevertheless, the temperature of the carbon bed 535 was able to be maintained predominantly at the desired target pyrolysis temperature $\left(550^{\circ} \mathrm{C}\right)$ 536 by the magnetron control system, except with some intermittent rises to $650{ }^{\circ} \mathrm{C}$ during 537 pyrolysis in the presence of metallic-char.

538 The sparks and the intermittent rises of temperature were likely to have been caused by 539 electrical arcing that occurred as a result of the metals present in the waste oil and those 540 metallic elements that were retained within the metallic-char (Table 3); the presence of 541 metals in the waste oil has been reported in previous works [6]. It has also been reported in 542 other microwave pyrolysis studies [23] that sparks (regarded as "microplasmas") were 543 observed during the heating of pyrolysis-char and they also exhibited a very high 544 temperature. In addition, the particles of metallic-char were observed to be incandescent 545 (exhibiting a bright-red color) against the background of dark waste oil within a dark 546 particulate-carbon bed, suggesting that they were transformed into hot spots (high 547 temperature sites) during the pyrolysis, probably due to their being more rapidly heated by 548 microwave radiation. These observations suggest that hot spots were formed during the 549 pyrolysis of the waste oil-char mixture, and they were most likely created as a result of the 550 addition of metallic-char to the reactor. The addition of metallic-char is thought to have an 551 effect on the pyrolysis of waste oil as the resulting hot spots could promote heterogeneous 552 reactions between the metallic-char and the waste oil (or the evolved pyrolysis-volatiles) and 553 lead to a different product composition. This is consistent with results from microwave 
554 pyrolysis studies of other materials, where the formation of $\mathrm{H}_{2}$ was observed even at a low 555 pyrolysis temperature of $500{ }^{\circ} \mathrm{C}[23,41,42]$. It can also be inferred from these results that

556 hot spots would form in the reactor if the microwave pyrolysis of waste oil (with no added 557 metallic-char) is performed in a continuous operation over a long period of time due to the 558 increased amount of metallic-char that is generated and remained trapped within the 559 particulate-carbon bed over a prolonged period of operation.

560 The temperature measured in the vapor zone (the space above the carbon bed in the reactor) 561 showed interesting results (Fig. 7). There was a slow increase of temperature to $\sim 150{ }^{\circ} \mathrm{C}$ as 562 the particulate-carbon bed was heated to the target temperature at $550{ }^{\circ} \mathrm{C}$, and this was 563 probably due to a convective heating effect resulting from the heating of the carbon bed by 564 microwave radiation and also the associated radiative heat transfer between the carbon bed 565 and the thermocouple. When the waste oil or the $80: 20 \mathrm{wt} \%$ mixture of waste oil and 566 metallic-char was added to reactor for pyrolysis treatment in a carbon bed at $550{ }^{\circ} \mathrm{C}$, there 567 was a sudden increase of temperature in the vapor zone from 150 to $200{ }^{\circ} \mathrm{C}$, and the 568 temperature remained at around this level throughout the remaining pyrolysis period. The 569 sudden rise of temperature was likely due to the evolution of hot pyrolysis-volatiles from the 570 waste oil that entered the vapor zone. The lower temperature in the vapor zone $\left(\sim 200{ }^{\circ} \mathrm{C}\right)$ 571 compared to the temperature in the particulate-carbon bed $\left(\geq 550^{\circ} \mathrm{C}\right)$ showed that different 572 temperature distributions are present within the reactor during the microwave pyrolysis and 573 this may be partly due to the continuous addition of cold $\mathrm{N}_{2}$ purge gas into the reactor. The 574 different heat distributions in different sections of the reactor may have effects on the reaction 575 pathways that occur in this pyrolysis process. 


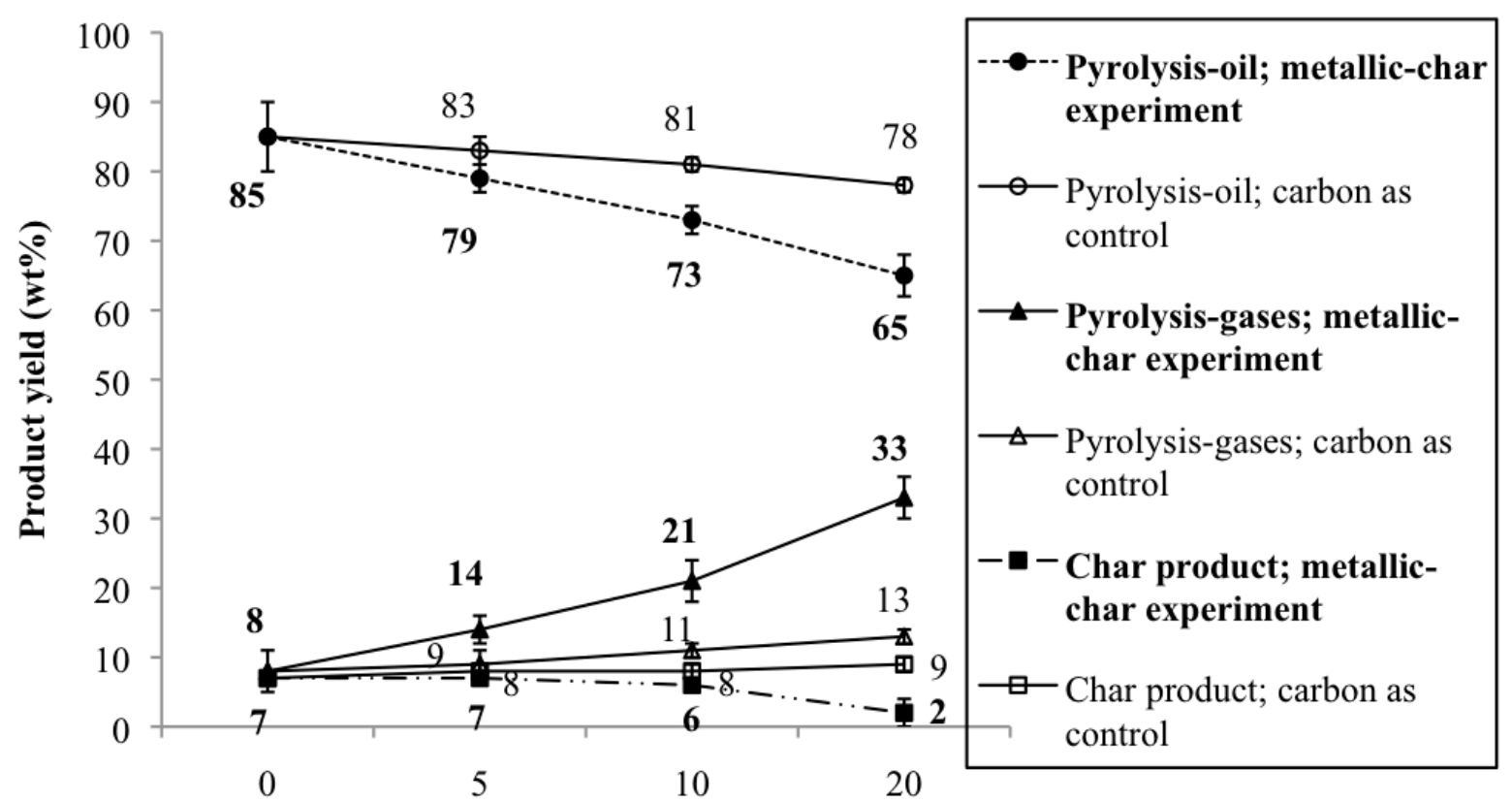

Amount of metallic-char or particulate-carbon (as control) added to waste oil (wt\% of the amount of waste oil added to the reactor)

578 Fig. 8. Product yields (wt $\%)$ as a function of the amount of metallic-char or particulatecarbon (as control) added to waste oil. Process conditions: Pyrolysis was performed on waste oil by contact with $1 \mathrm{~kg}$ of particulate-carbon bed when the effects of varying the amount of metallic-char added to the waste oil were studied, and all experiments were performed at a constant temperature of $550{ }^{\circ} \mathrm{C}$, waste oil feed rate of $1 \mathrm{~kg} / \mathrm{h}$, and $\mathrm{N}_{2}$ purge rate of 250 $583 \mathrm{ml} / \mathrm{min}$.

Metallic-char added with waste oil into the reactor

New char product

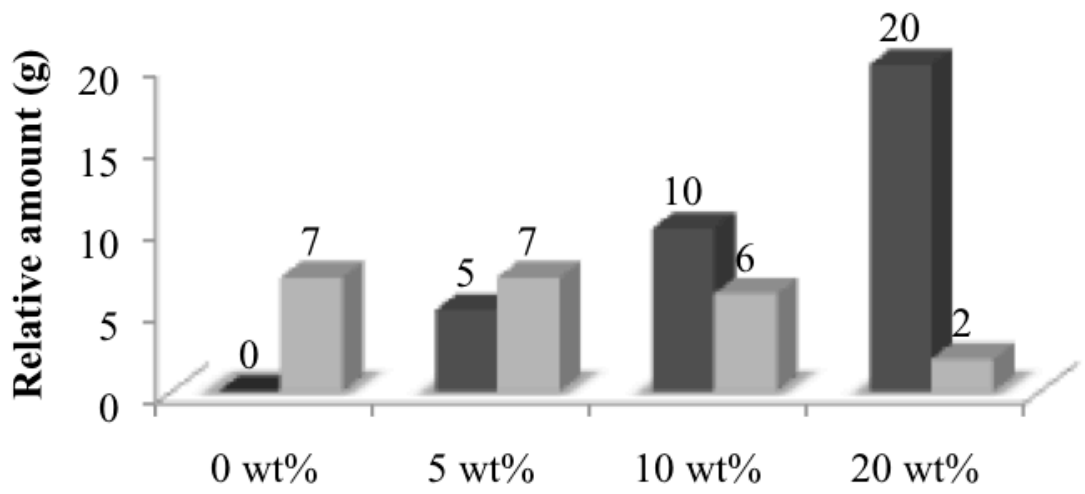

Amount of metallic-char added to waste oil (wt\% of the amount of waste oil added to the reactor)

Fig. 9. The relative amounts of metallic-char and char product as a function of the amount of metallic-char added to waste oil. 


\subsection{Product yield in the presence of metallic-char as catalyst}

590 Fig. 8 and Fig. 9 outline the effect of the amount of metallic-char on the fraction of waste

591 oil converted to pyrolysis-gases, pyrolysis-oil, and char product. The study showed that the

592 waste oils were thermally cracked to pyrolysis products dominated by pyrolysis-oil (65-85

593 wt.\%) and smaller amounts of pyrolysis-gases (8-33 wt.\%) and char product (2-7 wt.\%). The

594 amount of metallic-char was found to have a significant influence on the yields of pyrolysis

595 product. The yield of pyrolysis-gases was found to increase with increasing amounts of

596 metallic-char fed together with the waste oil into the reactor. Hot spots were observed on

597 addition of the waste oil-char mixture into the particulate-carbon bed during the pyrolysis

598 process (see Section 3.2). The formation of hot spots was likely to have promoted the

599 heterogeneous reactions between the metallic-char and the waste oil (or the evolved

600 pyrolysis-volatiles) to produce greater quantities of gases such as $\mathrm{H}_{2}$ and $\mathrm{CO}$ as reported by

601 others in microwave pyrolysis studies of other wastes [25, 43]. Thus, the presence of higher

602 amounts of metallic-char was likely to enhance the heterogeneous reactions that occurred

603 during the pyrolysis and this resulted in a higher yield of pyrolysis-gases and a lower

604 corresponding yield of pyrolysis-oil. However, the amount of new char production was found

605 to decrease with increasing amounts of metallic-char added to the waste oil (Fig. 4). This

606 could be explained by the gasification of the chars to produce $\mathrm{H}_{2}$ and $\mathrm{CO}$, this being one of

607 the heterogeneous reactions that have been reported to be highly promoted in microwave

608 pyrolysis systems $[14,15,20,24]$; this is likely to have contributed to the lower yield of the

609 new char product. The results show that the addition of metallic-char to the waste oil could

610 promote different product compositions due to additional heterogeneous reactions that

611 occurred during the pyrolysis in the presence of metallic-char.

612 
614 Table 4 demonstrates the main chemical components identified in the pyrolysis-oil and

615 pyrolysis-gases obtained from the experiments performed with different amounts of metallic-

616 char. The pyrolysis-oil comprised mainly of $\mathrm{C}_{5}-\mathrm{C}_{30}$ hydrocarbons, which were dominated by

617 aliphatic hydrocarbons (58-65 wt\%) and significant amounts of aromatic hydrocarbons (29-

$61838 \mathrm{wt} \%$ ). The composition of the pyrolysis-gases was dominated by aliphatic hydrocarbons

619 (58-78 vol\%) and significant amounts of permanent gases (i.e. $\mathrm{H}_{2}, \mathrm{CO}, \mathrm{CO}_{2}, \mathrm{H}_{2} \mathrm{~S}, 23-42$

620 vol\%). These results indicate the cracking of waste oil $\left(\mathrm{C}_{7}-\mathrm{C}_{41}\right.$ hydrocarbons; see Table 1) to

621 small hydrocarbon components $\left(\mathrm{C}_{1}-\mathrm{C}_{30}\right.$ hydrocarbons; see Table 4$)$, and the subsequent

622 formation of aromatics and permanent gases $\left(\mathrm{H}_{2}, \mathrm{CO}, \mathrm{CO}_{2}, \mathrm{H}_{2} \mathrm{~S}\right)$ through cracking,

623 aromatization, and heterogeneous reactions that were likely to have occurred during

624 pyrolysis. The production of pyrolysis-oil (comprising $\mathrm{C}_{5}$ to $\mathrm{C}_{20}$ aliphatic hydrocarbons) and

625 valuable gases such as $\mathrm{CH}_{4}, \mathrm{C}_{2} \mathrm{H}_{4}, \mathrm{H}_{2}$, and $\mathrm{CO}$ represents a potentially high-value chemical

626 feedstock or fuel source. The alkanes in the pyrolysis-oil could be upgraded to produce

627 transport-grade fuels, whereas the alkenes and aromatics constitute a feedstock that is highly

628 desired in the petrochemical industry, especially in plastic manufacture. The low heating

629 values (LHV) of the pyrolysis-gases was estimated based on the concentration of $\mathrm{CO}, \mathrm{H}_{2}$, and

$630 \mathrm{CH}_{4}$ in the pyrolysis-gases [44]. The pyrolysis-gases show a LHV ranging from 4.7 to 5.5

$631 \mathrm{MJ} / \mathrm{m}^{3}$, suggesting that the pyrolysis-gases could be used as a gaseous fuel and burned

632 directly in gas engines or fuel cells, or upgraded to produce hydrogen and synthetic fuel (via

633 a Fischer-Tropsch process). In particular, the hydrogen obtained can potentially be used as a

634 second-generation fuel or as a synthesis chemical, and the $\mathrm{CO}$ could be steam-reformed to

635 produce more hydrogen.

636

637

638 
640 Main chemical components identified in the pyrolysis-oil and pyrolysis-gases produced under 641 various conditions ${ }^{\mathrm{a}}$.

\begin{tabular}{|c|c|c|c|c|c|c|c|}
\hline & \multicolumn{7}{|c|}{ Metallic-char added to waste oil } \\
\hline & \multirow[t]{2}{*}{$0 \mathrm{wt} \%$} & \multicolumn{2}{|l|}{$5 \mathrm{wt} \%$} & \multicolumn{2}{|l|}{$10 \mathrm{wt} \%$} & \multicolumn{2}{|l|}{$20 \mathrm{wt} \%$} \\
\hline & & Control $^{b}$ & Treated & Control $^{b}$ & Treated & Control $^{b}$ & Treated \\
\hline $\begin{array}{l}\text { Pyrolysis-oil } \\
(\mathrm{wt} \%)\end{array}$ & & & & & & & \\
\hline Aliphatics ${ }^{c}$ & 65.1 & 64.6 & 63.6 & 63.9 & 61.5 & 62.2 & 57.5 \\
\hline Aromatics ${ }^{d}$ & 29.1 & 29.7 & 29.2 & 30.8 & 32.6 & 32.6 & 38.3 \\
\hline $\begin{array}{l}\text { Carbon } \\
\text { components }\end{array}$ & & & & & & & \\
\hline $\mathrm{C}_{5}-\mathrm{C}_{10}$ & 56.4 & 57.6 & 58.3 & 59.9 & 64.3 & 62.4 & 73.5 \\
\hline $\mathrm{C}_{11}-\mathrm{C}_{15}$ & 16.7 & 16.3 & 16.4 & 15.9 & 14.8 & 15.5 & 13.0 \\
\hline $\mathrm{C}_{16}-\mathrm{C}_{20}$ & 15.2 & 14.7 & 13.6 & 13.7 & 12.1 & 12.4 & 8.2 \\
\hline $\mathrm{C}_{21}-\mathrm{C}_{30}$ & 5.9 & 5.7 & 4.5 & 5.2 & 2.9 & 4.5 & 1.1 \\
\hline $\begin{array}{l}\text { Pyrolysis-gase } \\
\text { (vol\%) }\end{array}$ & & & & & & & \\
\hline $\mathrm{H}_{2}$ & 11.7 & 12.6 & 16.4 & 13.7 & 21.3 & 15.3 & 28.6 \\
\hline $\mathrm{CO}$ & 9.6 & 9.9 & 10.2 & 10.1 & 11.5 & 10.3 & 13.2 \\
\hline $\mathrm{CO}_{2}$ & 0.6 & 0.6 & 0.4 & 0.5 & 0.1 & 0.4 & 0.1 \\
\hline $\mathrm{H}_{2} \mathrm{~S}$ & 0.6 & 0.6 & 0.4 & 0.6 & 0.1 & 0.5 & $\mathbf{0 . 0}$ \\
\hline $\mathrm{CH}_{4}$ & 6.1 & 6.6 & 4.9 & 7.5 & 3.3 & 8.6 & 2.1 \\
\hline $\mathrm{C}_{2} \mathrm{H}_{2}$ & 0.2 & 0.2 & 0.2 & 0.2 & 0.1 & 0.2 & 0.1 \\
\hline $\mathrm{C}_{2} \mathrm{H}_{4}$ & 21.5 & 21.9 & 23.8 & 23.5 & 30.9 & 25.8 & 34.0 \\
\hline $\mathrm{C}_{2} \mathrm{H}_{6}$ & 2.5 & 2.5 & 2.1 & 2.5 & 1.4 & 2.2 & 0.9 \\
\hline $\mathrm{C}_{3} \mathrm{H}_{6}$ & 10.2 & 11.5 & 14.0 & 12.6 & 17.5 & 13.9 & 19.3 \\
\hline $\mathrm{C}_{3} \mathrm{H}_{8}$ & 0.1 & 0.2 & 0.1 & 0.3 & 0.1 & 0.5 & 0.2 \\
\hline $\mathrm{C}_{4} \mathrm{H}_{6}$ & 8.7 & 7.6 & 6.8 & 6.9 & 3.1 & 4.9 & 0.5 \\
\hline $\mathrm{C}_{4} \mathrm{H}_{8}$ & 15.5 & 14.3 & 11.9 & 10.9 & 6.1 & 8.8 & 0.6 \\
\hline $\mathrm{C}_{4} \mathrm{H}_{10}$ & 0.6 & 0.6 & 0.5 & 0.7 & 0.3 & 0.8 & 0.2 \\
\hline $\mathrm{C}_{5 \text { and }} \mathrm{C}_{6}{ }^{\mathrm{e}}$ & 12.7 & 11.5 & 8.3 & 9.5 & 4.2 & 7.6 & 0.2 \\
\hline $\mathrm{C}_{1}-\mathrm{C}_{6}{ }^{\mathrm{f}}$ & 78.1 & 76.9 & 72.6 & 74.6 & 67.0 & 73.3 & 58.1 \\
\hline LHV $\left(\mathrm{MJ} / \mathrm{m}^{3}\right)$ & 4.7 & - & 4.8 & - & 4.9 & & 5.5 \\
\hline
\end{tabular}

642

643

644

645

646

647

648

649

650

651

652

653

654

655

656

a Process conditions: Pyrolysis was performed on waste oil by contact with $1 \mathrm{~kg}$ of particulate-carbon bed when the effects of varying the amount of metallic-char added to the waste oil were studied, and all experiments were performed at a constant temperature of $550^{\circ} \mathrm{C}$, waste oil feed rate of $1 \mathrm{~kg} / \mathrm{h}$, and $\mathrm{N}_{2}$ purge rate of $250 \mathrm{ml} / \mathrm{min}$.

${ }^{\mathrm{b}}$ Particulate-carbon was used as a control.

${ }^{\mathrm{c}}$ Aliphatics -alkanes, naphthenes, alkenes, dialkenes.

${ }^{\mathrm{d}}$ Aromatics - benzene, toluene, xylene, alkyl-benzenes.

${ }^{\mathrm{e}} \mathrm{C}_{5}$ and $\mathrm{C}_{6}$ compounds detected in the pyrolysis-gases are grouped and presented in a total value.

${ }^{\mathrm{f}}$ The sum of $\mathrm{C}_{1}-\mathrm{C}_{6}$ aliphatic hydrocarbons.

$\mathrm{g}$ Low heating value (LHV) of the gas product $\left(\mathrm{kJ} / \mathrm{m}^{3}\right)$ is calculated based on the concentration of $\mathrm{CO}, \mathrm{H}_{2}$, and $\mathrm{CH}_{4}$ in the pyrolysis-gases [44], i.e. $\left[\left(30^{*} \mathrm{CO}\right)+\left(25.7^{*} \mathrm{H}_{2}\right)+\right.$ $\left.\left(85.4 * \mathrm{CH}_{4}\right)\right] \times 4.2$.

657 influence on the chemical composition of the pyrolysis-oil and pyrolysis-gases. Increasing the 
amount of metallic-char led to an increase in aromatic content along with a decrease in

659 aliphatic content in the pyrolysis-oil, and the hydrocarbon content improved towards the

660 presence of smaller hydrocarbon chains $\left(\mathrm{C}_{5}-\mathrm{C}_{10}\right)$. The increase in the amount of metallic-char

661 also resulted in greater production of $\mathrm{H}_{2}$ and $\mathrm{CO}$ in the pyrolysis-gases (up to 42 vol\% of

$662 \mathrm{H}_{2}+\mathrm{CO}$ ). This was accompanied by a decrease in $\mathrm{CO}_{2}$ and aliphatic contents in the pyrolysis-

663 gases with the composition of the aliphatics being improved towards the presence of smaller

664 hydrocarbon chains $\left(\leq \mathrm{C}_{3}\right)$. The yields of $\mathrm{H}_{2}, \mathrm{CO}, \mathrm{C}_{2} \mathrm{H}_{4}$, and $\mathrm{C}_{3} \mathrm{H}_{6}$ were found to increase with

665 increasing amounts of metallic-char; these compounds are believed to comprise the bulk of

666 the increased amount of pyrolysis-gases produced when higher amounts of metallic-char

667 were added to the waste oil before the pyrolysis. In contrast, a reduction in $\mathrm{CO}_{2}$ content was

668 observed although $\mathrm{CO}_{2}$ was detected only in minor quantities $(\leq 0.6$ vol\%), and this was also

669 accompanied by a reduction in $\mathrm{CH}_{4}$ content.

670 In this study, the increase in the amount of metallic-char added to the waste oil was thought

671 to have led to the formation of hot spots within the reactor (see Section 3.2), and in turn

672 promoted heterogeneous reactions between the metallic-char and the waste oil (or the evolved

673 pyrolysis-volatiles) to produce greater yields of $\mathrm{H}_{2}$ and $\mathrm{CO}$ and lower yields of $\mathrm{CO}_{2}$ and $\mathrm{CH}_{4}$.

674 In addition, the hot spots created by the metallic-char (homogeneously mixed with the waste

675 oil) appeared to promote cracking reactions during the pyrolysis and resulted in the observed

676 formation of higher amounts of lighter hydrocarbons in both the pyrolysis-oil (i.e. $\mathrm{C}_{5}-\mathrm{C}_{10}$

677 hydrocarbons) and pyrolysis-gases (i.e. $\leq \mathrm{C}_{3}$ hydrocarbons). This agrees with the findings

678 reported by other researchers working on microwave pyrolysis studies of other materials [15,

$67925,43]$, which propose that char particles may absorb microwave energy and heat up, then

680 transform into hot spots, which in turn act in a catalytic manner to promote the cracking and

681 heterogeneous reactions during the microwave pyrolysis process, e.g. the decomposition

682 reactions of hydrocarbons to produce $\mathrm{H}_{2}$, and the aromatization reactions to generate $\mathrm{H}_{2}$ and 
benzene [8].

684 The catalytic effect could also be attributed to the high surface area $\left(124 \mathrm{~m}^{2} / \mathrm{g}\right)$ and the 685 presence of metals and metal oxides in the metallic-char (Table 3), the amounts of which are 686 likely to increase with increasing amounts of metallic-char added to the waste oil, providing 687 more reaction sites in order for these reactions to occur. The metallic-char was likely to act as 688 an intermediate reductant that had reduced the adsorbed metals or metal oxides into metallic 689 states which in turn enhanced the cracking and heterogeneous reactions that occurred during 690 the pyrolysis process.

691 Furthermore, the catalytic activity of metallic-char could be explained by a microwave692 specific mechanism. As previously observed by others in microwave pyrolysis studies [17, $69318,23,45,46]$, the interaction of the electromagnetic microwave field with particular types of 694 carbon (e.g. metallic-char) generates "microplasmas" (i.e. electrical discharges resulting 695 from the rapidly oscillating electromagnetic microwave field) which create charge 696 imbalances that are restricted by the physical boundaries of the carbon particles. The 697 temperature of these microplasmas is considerably higher than that of the bulk carbon bed, 698 and consequently waste oil exposed to these microplasmas will be cracked to a greater extent. 699 Such microplasmas were observed during pyrolysis in the additional presence of the metallic700 char (pre-mixed with waste oil), but not at all when pyrolysis was conducted with only the 701 waste oil (i.e. in the absence of added metallic-char). Thus, it is likely that this additional 702 mechanism due to the presence of microplasmas contributed to the additional cracking 703 observed when using the waste oil-char mixture.

704

3.5. Possible chemical reaction mechanisms accounting for the catalytic conversion of waste 706 oil using the metallic-char catalyst coupled with microwave pyrolysis.

707 The results have shown that microwave pyrolysis in the presence of the metallic-char as the 
708 catalyst cracked the waste oil to produce a unique product distribution of compounds 709 comprising predominantly light hydrocarbons, $\mathrm{H}_{2}$ and $\mathrm{CO}$ gases, and char product in the 710 pyrolysis products. The production of these compounds could derive mainly from the primary 711 and secondary pyrolysis cracking reactions occurring via a free-radical-induced mechanism 712 [10-12], and secondary reactions comprising both homogenous and heterogeneous reactions 713 such as Diels-Alder type aromatization reactions (i.e. condensation, dehydrogenation), 714 reforming, dehydrogenation, decomposition, gasification, carbon reduction, and 715 carbonization.

716 The wide distribution of aliphatic chains in the pyrolysis products supports the proposed 717 free-radical-induced random scission mechanism for the catalytic pyrolytic cracking of waste 718 oil; the reaction mechanism, comprising random scission reaction, H-atom-abstraction 719 reactions, $\beta$-scission reaction, and termination reactions, has also been proposed for the 720 pyrolysis of polyolefins based on the wide distribution of aliphatic chains found in the 721 pyrolysis products [47-50]. Hydrocarbon radicals were likely to be generated from this 722 mechanism through which the radicals were then stabilized by the capture of hydrogen atoms 723 from the molecules nearby and this resulted in the conversion of heavy hydrocarbons in the 724 waste oil into lighter hydrocarbons by $\mathrm{H}$-atom abstraction and $\beta$-scission reactions; this 725 accounts for the light aliphatic hydrocarbons detected in both the pyrolysis-oil and pyrolysis726 gases. The free-radical mechanism could proceed further during the pyrolysis cracking of 727 waste oil whereby the large aliphatic hydrocarbons (e.g. large alkenes) might undergo 728 secondary pyrolysis cracking and decompose to form aliphatic hydrocarbons of shorter 729 chains as proposed by Miller [51]. The short-chained aliphatic hydrocarbons (e.g. alkenes and 730 dialkenes) produced from the free-radical-induced random scission mechanism could then 731 proceed to form aromatic hydrocarbons observed in the pyrolysis products by Diels-Alder 732 type aromatization reactions, which involve condensation of alkenes followed by 
733 dehydrogenation to form aromatic hydrocarbons. Depending on the extent of these secondary

734 actions and the amount of thermal energy generated by the microwave radiation at the

735 pyrolysis temperature, carbonization could occur and lead to the production of carbonaceous

736 char as the char product.

737 The production of permanent gases species (e.g. $\mathrm{H}_{2}, \mathrm{CO}, \mathrm{CO}_{2}$ ) and char product could be

738 attributed to the secondary reactions occurring either homogeneously or heterogeneously in

739 the presence of the metallic-char as the catalyst during the pyrolysis process. The proposed

740 secondary reactions are termed as R1 - R11 as below:

741 Pyrolysis cracking of hydrocarbons: $\mathbf{C}_{\mathbf{x}} \mathbf{H}_{\mathbf{y}} \rightarrow \frac{\mathbf{y}}{2} \mathbf{H}_{\mathbf{2}}+\mathbf{x} \mathbf{C}_{\mathbf{c h a r}}$

742 Diels-Alder type aromatization: $\quad \mathbf{C}_{\mathbf{x}} \mathbf{H}_{\mathbf{y}} \rightarrow \frac{\mathbf{x}}{6} \mathbf{C}_{\mathbf{6}} \mathbf{H}_{\mathbf{6}}+(\mathbf{2 y}-\mathbf{x}) \mathbf{H}_{2}$

743 Dehydrogenation: $\mathbf{C}_{\mathbf{n}} \mathbf{H}_{2 \mathbf{n}+2} \rightarrow \mathbf{C}_{\mathbf{n}} \mathbf{H}_{2 \mathbf{n}}+\mathbf{H}_{2}$

$744 \quad(\mathrm{R} 3)$

745 Methane decomposition: $\mathbf{C H}_{\mathbf{4}} \rightarrow \mathbf{C}_{\mathbf{c h a r}}+\mathbf{2} \mathbf{H}_{\mathbf{2}}$

746 Steam reforming: $\mathbf{C}_{\mathbf{x}} \mathbf{H}_{\mathbf{y}}+\mathbf{x ~ H}_{\mathbf{2}} \mathbf{O} \rightarrow \mathbf{x} \mathbf{C O}+\left(\mathbf{x}+\frac{\mathbf{y}}{2}\right) \mathbf{H}_{2}$

747 Steam reforming of methane: $\mathbf{C H}_{\mathbf{4}}+\mathbf{H}_{\mathbf{2}} \mathbf{O} \leftrightarrow \mathbf{C O}+\mathbf{3} \mathbf{H}_{2}$

$748 \quad(\mathrm{R} 6)$

749 Steam gasification: $\mathbf{C}_{\text {char }}+\mathbf{H}_{\mathbf{2}} \mathbf{O} \rightarrow \mathbf{C O}+\mathbf{H}_{2}$

750 Dehydrogenation of hydrocarbons: $\left(-\mathbf{C H}_{2}-\right)+\mathbf{C O}_{2} \leftrightarrow 2 \mathbf{C O}+\mathbf{H}_{2}$

751 Dry-reforming of hydrocarbons: $\mathbf{C H}_{4}+\mathbf{C O}_{2} \leftrightarrow 2 \mathbf{C O}+\mathbf{2} \mathbf{H}_{2}$

752 Reduction of metal ions $\left(\mathrm{Me}^{2+}\right)$ and metallic oxides $\left(\mathrm{Me}_{\mathrm{m}} \mathrm{O}_{\mathrm{n}}\right)$ to metal $(\mathrm{Me})$ by carbon:

$753 \mathrm{C}+\mathrm{Me}^{2+} \rightarrow \mathrm{Me}+\mathrm{C}^{2+}$

$754 \mathrm{nC}+\mathrm{Me}_{\mathrm{m}} \mathrm{O}_{\mathrm{n}} \rightarrow \mathrm{m} \mathrm{Me}+\mathrm{nCO}$

$755 \mathrm{H}_{2}$ gas was likely to be generated via the catalytic heterogeneous reactions (R1, R2)

756 occurring between the metallic-char and the waste oil or the evolved pyrolysis-volatiles [14,

$75715,24,41]$, since significant amount of $\mathrm{H}_{2}$ (up to 29 vol\%) was detected in the pyrolysis- 
gases (Table 4). In addition, the decreasing yield of aliphatic hydrocarbons with increasing amount of metallic-char added to the pyrolysis process (Table 4) suggest that it was the

760 increased occurrence of the R1 and R2 reactions that had converted some of the aliphatic 761 hydrocarbons into $\mathrm{H}_{2}$ and aromatics, resulting in higher yields of these compounds detected 762 in the pryolysis products; this supports the occurrence of the proposed catalytic 763 heterogeneous reactions $(\mathrm{R} 1, \mathrm{R} 2)$ for $\mathrm{H}_{2}$ formation. Al-containing catalyst has been reported 764 to have the ability to enhance aromatization reactions (R2) in producing aromatics [52], thus 765 the increasing amount of metallic-char containing Al (Table 3) was likely to have promoted 766 the R2 reactions to generate higher yield of aromatics as observed in the pyrolysis-oil.

767 The high yield of ethylene observed in the pyrolysis-gases (up to 34 vol\%, Table 4) was 768 likely to arise from the dehydrogenation of ethane to ethylene (R3) during the catalytic 769 microwave pyrolysis of the waste oil. This reaction was found to be promoted under the 770 influence of microwave heating within microwave pyrolysis systems $[14,16,24]$; this also 771 contributes to the higher yield of $\mathrm{H}_{2}$ and lower yield of ethane observed in the pyrolysis-gases 772 (Table 4). In addition, the presence of metals and metal oxides such as $\mathrm{Al}$ and $\mathrm{Al}_{2} \mathrm{O}_{3}$ were 773 reported to have a catalytic effect on this reaction [19]. The increase in the amount of 774 metallic-char added to the waste oil led to the presence of higher amounts of these metal 775 elements in the reactor, thus promoting the occurrence of dehydrogenation reactions and 776 resulting in the increased yields of ethylene observed in the pyrolysis-gases; this also 777 contributes to the increased yield of $\mathrm{H}_{2}$ and lower yield of ethane.

778 A reduction in $\mathrm{CH}_{4}$ content was observed with an increase in the amount of metallic-char 779 added to the waste oil (Table 4), suggesting that a portion of the $\mathrm{CH}_{4}$ was transformed into $\mathrm{H}_{2}$ 780 by the methane decomposition reactions (R4) that occurred during the pyrolysis; this also 781 contributes to the production of char product and the increased yield of $\mathrm{H}_{2}$ during the 782 pyrolysis. This reaction was found to be promoted under the influence of microwave heating 
783 and the formation of hot spots within the microwave pyrolysis system [43]. In addition, 784 carbon materials and metal-containing catalysts (e.g. Fe- $\mathrm{Al}_{2} \mathrm{O}_{3}, \mathrm{Ni}, \mathrm{Al}$ ) were reported to show 785 catalytic effects on this reaction [21,22]. The use of metallic-char as a catalyst followed by 786 the formation of hot spots by the addition of the carbonaceous metallic-char containing $\mathrm{Fe}$, $787 \mathrm{Ni}, \mathrm{Al}_{2} \mathrm{O}_{3}$, (see Table 3 and Fig. 5) support the proposed occurrence of methane 788 decomposition reactions for the formation of char product and $\mathrm{H}_{2}$.

789 Th waste oil used in this study was found to contain a certain amount of water (about 20 $790 \mathrm{wt} \%)$; the presence of water in the waste oil has been reported in previous work [8]. The 791 water could vaporise as steam during the pyrolysis process by the microwave heating. This 792 could lead to the occurrence of steam reforming reaction of hydrocarbons (R5, R6) and the 793 steam gasification of chars (R7), resulting in higher production of $\mathrm{H}_{2}$ and $\mathrm{CO}$ in the pyrolysis 794 gases (Table 4). It has been reported that catalysts containing $\mathrm{Mg}$ could enhance 795 heterogeneous reactions such as steam gasification and reforming reactions [53]; the use of 796 metallic-char containing Mg (see Table 3 and Fig. 5) supports the proposed occurrence of 797 these reactions.

$798 \mathrm{CO}_{2}$ was only detected in less than $0.6 \mathrm{vol} \%$ (Table 4), whereas higher quantities of $\mathrm{CO}$ 799 were detected in the pyrolysis-gases (up to $13 \mathrm{vol} \%$ ), suggesting that a significant portion of 800 the $\mathrm{CO}_{2}$ might be converted to form $\mathrm{H}_{2}$ and $\mathrm{CO}$ by heterogeneous reactions such as 801 dehydrogenation (R8) and dry-reforming (R9) reactions that have been reported to be 802 promoted under microwave pyrolysis environment $[14,15]$. Both the concentrations of $\mathrm{CO}_{2}$ 803 and aliphatic hydrocarbons (particularly $\mathrm{CH}_{4}$ ) were found to decrease when using increased 804 amounts of the metallic-char (Table 4). This supports the proposed increased occurrence of 805 these heterogeneous reactions that had resulted in higher productions of $\mathrm{H}_{2}$ and $\mathrm{CO}$ in the 806 pyrolysis-gases.

807 The results revealed that the increase in the amount of metallic-char added to the waste oil 
808 led to a reduction in the subsequent yield of additional char product (Fig. 9), suggesting that a 809 portion of the char product (generated by the decomposition of hydrocarbons, R1 and R4)

810 was converted to $\mathrm{H}_{2}$ and $\mathrm{CO}$ by gasification reactions (R7). These gasification reactions were

811 likely to occur due to the ability of the metallic-char to absorb the microwave energy and heat

812 up, transforming into hot spots and in turn promoting the occurrence of these reactions. These

813 gasification reactions are a few of the heterogeneous reactions that were reported to be highly

814 promoted in microwave pyrolysis systems [14, 25], and they were found to occur in

815 microwave pyrolysis systems even at low reaction temperatures of 400 and $500{ }^{\circ} \mathrm{C}$ [42], thus

816 the yield of char product was reduced in favour of $\mathrm{H}_{2}$ and $\mathrm{CO}$ formation.

817 In this study, the addition of metallic-char to the waste oil was found to have a catalytic 818 effect on both the cracking and the heterogeneous reactions that occurred during the 819 pyrolysis, converting the waste oil (or the evolved pyrolysis-volatiles) into light 820 hydrocarbons, $\mathrm{H}_{2}$ and $\mathrm{CO}$ gases; this helps to explain the higher production of $\mathrm{H}_{2}$ and $\mathrm{CO}$ 821 gases, and also the higher yields of smaller hydrocarbon chains $\left(\mathrm{C}_{5}-\mathrm{C}_{10}\right.$ hydrocarbons, $\mathrm{CH}_{4}$, $\left.822 \mathrm{C}_{2} \mathrm{H}_{4}\right)$ observed in both the pyrolysis-oil and pyrolysis-gases. The results suggest that the 823 reactions in catalytic microwave pyrolysis of waste oil are a combination of primary and 824 secondary pyrolysis cracking, and serial and parallel secondary reactions occurring 825 homogenously or heterogeneously as described by R1 - R11, with the pyrolysis cracking and 826 catalytic heterogeneous reactions dominating as metallic-char is incorporated into the 827 pyrolysis process, resulting in a relatively high reaction selectivity toward $\mathrm{H}_{2}, \mathrm{CO}$, and a 828 desirable lighter hydrocarbon fraction in the pyrolysis products 


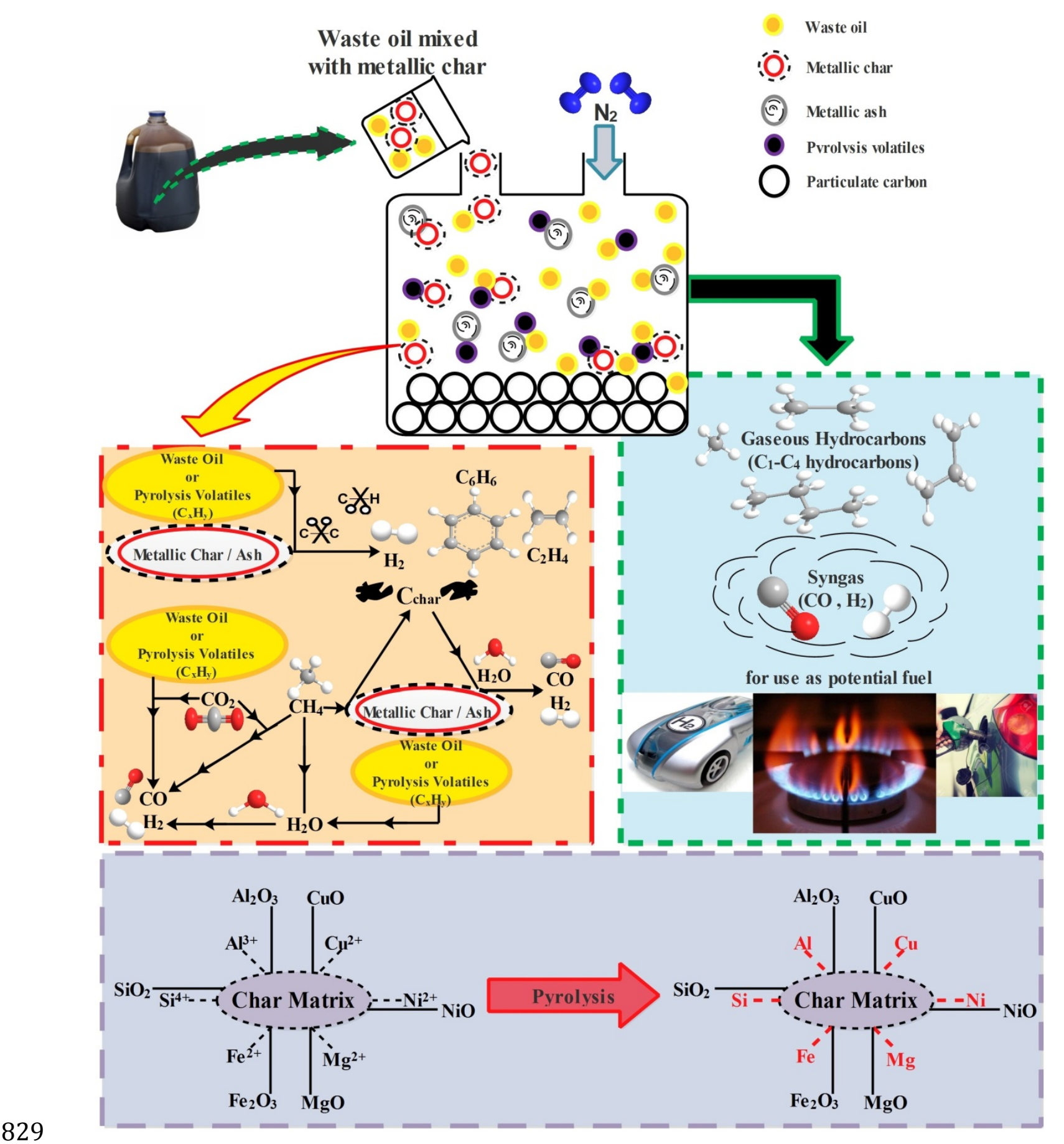

Fig. 10. Reaction mechanisms accounting for microwave pyrolysis conversion of waste oil using the metallic char catalyst.

834 Fig. 10 summarizes the mechanisms involved in the microwave pyrolysis conversion of 835 waste oil through the use of the metallic-char as a catalyst. In this microwave pyrolysis 836 process, the metallic-char initially acted as an adsorptive-support to adsorb metals, metal oxides and waste oil. Then, the char became a microwave absorbent that absorbed microwave 
energy and heated up to high temperature in a short time and in turn transformed into hot spots (high temperature sites) under the influence of microwave heating. The presence of this high temperature metallic-char had provided a reducing chemical environment in which the

841 metallic-char acted an intermediate reductant to reduce the adsorbed metals or metal oxides 842 into metallic states (R10, R11) which then functioned as a catalyst to provide more reaction 843 sites that enhanced the cracking and heterogeneous reactions that occurred during the pyrolysis to convert the waste oil into producing higher yields of light hydrocarbons, $\mathrm{H}_{2}$ and

$845 \mathrm{CO}$ gases in the pyrolysis products. It should be noted that the metals contained in the 846 metallic-char could be regenerated by gasification or thermal regeneration of the metallic847 char since the metals should remain in solid states considering their high sublimation 848 temperatures $\left(\geq 1000{ }^{\circ} \mathrm{C}\right.$, e.g. $2732^{\circ} \mathrm{C}$ for $\mathrm{Ni}$ and $1535^{\circ} \mathrm{C}$ for $\left.\mathrm{Fe}\right)[38]$.

849 The results in this study have indicated that the use of metallic-char obtained from the previous pyrolysis of waste oil as a catalyst showed a significant influence on the product

851 distribution in this pyrolysis process and led to the production of useful light hydrocarbons, $852 \mathrm{H}_{2}$ and $\mathrm{CO}$ gases in the pyrolysis products. The use of metallic-char combined with 853 microwave pyrolysis showed advantages in enhancing the reaction rates and the selectivities 854 of the products. This presents new information on the use of metallic-char as a catalyst in microwave pyrolysis treatment of problematic waste oils. It can also be inferred from these results that if the microwave pyrolysis of waste oil were performed in a continuous operation

857 over a long period of time, the increased amount of metallic-char that would be generated and 858 trapped within the particulate-carbon bed would exert a similar catalytic influence and 859 promote altering product compositions due to enhanced cracking and heterogeneous reactions occurring as a result of the formation of hot spots within the reactor. 


\section{Conclusion}

864 The metallic-char catalyst demonstrated a highly porous structure and was found to contain 865 phases of metals and metal oxides. Combined with the results showing high surface area and 866 thermal stability in a $\mathrm{N}_{2}$ atmosphere, this makes the metallic-char a potentially suitable 867 catalyst to be used in pyrolysis cracking process. The use of the metallic-char as a catalyst in 868 the microwave pyrolysis of waste oil was found to have strong influence on the fraction of 869 waste oil converted to pyrolysis-oil and pyrolysis-gases. The addition of the metallic-char 870 also influenced the concentrations and molecular nature of the wide variety of compounds 871 formed in the pyrolysis-oil and pyrolysis-gases. An increase in the amount of metallic-char 872 catalyst resulted in the formation of hot spots within the reactor in which the high temperature metallic-char provided a reducing chemical environment to reduce the adsorbed metals or metal oxides into metallic states, which appear to act catalytically in providing more reactions sites in order for cracking and heterogeneous reactions to occur during the

876 pyrolysis process. Higher yields of light hydrocarbons, $\mathrm{H}_{2}$ and $\mathrm{CO}$ gases were obtained in the pyrolysis products in the presence of higher amounts of metallic-char. The addition of metallic-char catalyst equivalent to $20 \mathrm{wt} \%$ of the amount of waste oil added to the reactor generated a $65 \mathrm{wt} \%$ yield of pyrolysis-oil containing $\mathrm{C}_{5}-\mathrm{C}_{20}$ hydrocarbons in addition to a 33 wt $\%$ yield of pyrolysis-gases comprising 58 vol\% of $\mathrm{C}_{1}-\mathrm{C}_{6}$ hydrocarbons and $42 \mathrm{vol} \%$ of $\mathrm{H}_{2}$ and $\mathrm{CO}$ gases, representing a potential source of high-value fuel and syngas. These results demonstrate that the metallic-char catalyst showed advantages in transforming the waste oil into potential fuel products, and thus showing excellent potential for use as a catalyst in microwave pyrolysis treatment of problematic waste oils.

\section{Acknowledgements}

887 The authors acknowledges the financial support by the Ministry of Science, Technology, 
and Innovation Malaysia (MOSTI), Ministry of Higher Education Malaysia (MOHE), and

University Malaysia Terengganu for the conduct of the research under the E-Science fund

(UMT/RMC/SF/13/52072(5), Vot No: 52072), the Fundamental Research Grant Scheme 891

(Project No: FRGS/1/2013/TK05/UMT/02/2, Vot No: 59296), and the Research 892 Acculturation Grant Scheme (Project No: RAGS/2012/UMT/TK07/3, Vot No: 57085).

893

\section{References}

895

896

897

898

899

900

901

902

903

904

905

906

907

908

909

910

911

912

913

914 915

916 917

[1] M.a.F. Gómez-Rico, I. Martín-Gullón, A. Fullana, J.A. Conesa, R. Font, J. Anal. Appl. Pyrolysis 68-69 (2003) 527-546.

[2] M.J. Fuentes, R. Font, M.F. Gómez-Rico, I. Martín-Gullón, J. Anal. Appl. Pyrolysis 79 (2007) 215-226.

[3] F. Audibert, Waste engine oils: rerefining and energy recovery, 1st ed., Elsevier B.V., Amsterdam, 2006.

[4] D.W. Brinkman, J.R. Dickson, Environ. Sci. Technol. 29 (1995) 81-86.

[5] S.S. Lam, A.D. Russell, H.A. Chase, Energy 35 (2010) 2985-2991.

[6] S.S. Lam, A.D. Russell, H.A. Chase, Ind. Eng. Chem. Res. 49 (2010) 10845-10851.

[7] M.-A. Franco-Nava, J.-P. Blancheton, G. Deviller, J.-Y. Le-Gall, Aquacult. Eng. 31 (2004) 135-155.

[8] S.S. Lam, A.D. Russell, C.L. Lee, S.K. Lam, H.A. Chase, Int. J. Hydrog. Energy 37 (2012) 5011-5021.

[9] S.S. Lam, A.D. Russell, C.L. Lee, H.A. Chase, Fuel 92 (2012) 327-339.

[10] F.O. Rice, J. Am. Chem. Soc. 55 (1933) 3035-3040.

[11] F.O. Rice, K.F. Herzfeld, J. Am. Chem. Soc. 56 (1934) 284-289.

[12] F.O. Rice, M.D. Dooley, J. Am. Chem. Soc. 55 (1933) 4245-4247.

[13] D.A. Jones, T.P. Lelyveld, S.D. Mavrofidis, S.W. Kingman, N.J. Miles, Resour. Conserv. Recycl. 34 (2002) 75-90.

[14] Y. Fernández, A. Arenillas, J.M. Bermúdez, J.A. Menéndez, J. Anal. Appl. Pyrolysis 88 (2010) 155-159.

[15] Y. Fernández, A. Arenillas, M.A. Díez, J.J. Pis, J.A. Menéndez, J. Anal. Appl. Pyrolysis 84 (2009) $145-150$. 
[16] W. Zuo, Y. Tian, N. Ren, Waste Manage. 31 (2011) 1321-1326.

919 [17] S.S. Lam, H.A. Chase, Energies 5 (2012) 4209-4232.

920

921

922

923

924

925

926

927

928

929

930

931

932

933

934

935

936

937

938

939

940

941

942

943

944

945

946

947

948

949

950

[18] A.D. Russell, E.I. Antreou, S.S. Lam, C. Ludlow-Palafox, H.A. Chase, RSC Advances 2 (2012) 6756-6760.

[19] E. Udalov, V. Bolotov, Y. Tanashev, Y. Chernousov, V. Parmon, Theoretical and Experimental Chemistry 46 (2011) 384-392.

[20] A. Domínguez, J.A. Menéndez, M. Inguanzo, J.J. Pís, Bioresource Technol. 97 (2006) 1185-1193.

[21] N. Muradov, F. Smith, A. T-Raissi, Catal. Today 102-103 (2005) 225-233.

[22] L.B. Avdeeva, T.V. Reshetenko, Z.R. Ismagilov, V.A. Likholobov, Applied Catalysis A: General 228 (2002) 53-63.

[23] J.A. Menéndez, A. Domínguez, Y. Fernández, J.J. Pis, Energ. Fuel. 21 (2007) 373-378.

[24] A. Domínguez, J.A. Menéndez, Y. Fernández, J.J. Pis, J.M.V. Nabais, P.J.M. Carrott, M.M.L.R. Carrott, J. Anal. Appl. Pyrolysis 79 (2007) 128-135.

[25] A. Domínguez, Y. Fernández, B. Fidalgo, J.J. Pis, J.A. Menéndez, Chemosphere 70 (2008) 397-403.

[26] O. Arpa, R. Yumrutas, Fuel Process. Technol. 91 (2010) 197-204.

[27] A. Sinağ, S. Gülbay, B. Uskan, S. Uçar, S.B. Özgürler, J. Hazard. Mater. 173 (2010) 420-426.

[28] G.-J. Song, Y.-C. Seo, D. Pudasainee, I.-T. Kim, Waste Manage. 30 (2010) 1230-1237.

[29] A. Lea-Langton, N. Giannakeas, G. Rickett, V. Dupont, M. Twigg, SAE International Journal of Fuels and Lubricants 3 (2010) 810-818.

[30] ASTM Standard E1131-08, Standard Test Method for Compositional Analysis by Thermogravimetry, ASTM International, West Conshohocken, PA, 2008.

[31] M.J. Lázaro, R. Moliner, C. Domeño, C. Nerín, J. Anal. Appl. Pyrolysis 57 (2001) 119131.

[32] Q. Xie, P. Peng, S. Liu, M. Min, Y. Cheng, Y. Wan, Y. Li, X. Lin, Y. Liu, P. Chen, R. Ruan, Bioresource Technol. 172 (2014) 162-168.

[33] J.A. Menéndez, E.M. Menéndez, A. Garcia, J.B. Parra, J.J. Pis, J. Microwave. Power. EE. 34 (1999) 137-143.

[34] P.H. Blanco, C. Wu, J.A. Onwudili, P.T. Williams, Applied Catalysis B: Environmental 134-135 (2013) 238-250.

[35] I.F. Elbaba, P.T. Williams, Applied Catalysis B: Environmental 125 (2012) 136-143. 
951

952

953

954

955

956

957

958

959

960

961

962

963

964

965

966

967

968

969

970

971

972

973

974

975

976

977

978

979

980

[36] A. López, I. de Marco, B.M. Caballero, M.F. Laresgoiti, A. Adrados, A. Aranzabal, Applied Catalysis B: Environmental 104 (2011) 211-219.

[37] S. Brunauer, L. Deming, W. Deming, E. Teller, J. Am. Chem. Soc 62 (1940) 1723.

[38] Y. Shen, P. Zhao, Q. Shao, D. Ma, F. Takahashi, K. Yoshikawa, Applied Catalysis B: Environmental 152-153 (2014) 140-151.

[39] J.C. Acomb, C. Wu, P.T. Williams, Applied Catalysis B: Environmental 147 (2014) 571-584.

[40] C. Wu, P.T. Williams, Applied Catalysis B: Environmental 90 (2009) 147-156.

[41] X. Zhang, D.O. Hayward, Inorg. Chim. Acta 359 (2006) 3421-3433.

[42] T. Karayildirim, J. Yanik, M. Yuksel, H. Bockhorn, Fuel 85 (2006) 1498-1508.

[43] J.A. Menéndez, A. Domínguez, M. Inguanzo, J.J. Pis, J. Anal. Appl. Pyrolysis 71 (2004) 657-667.

[44] H.P. Kuo, S.M. Pan, H.T. Hsu, Biomass Bioenergy 35 (2011) 3025-3031.

[45] E.A. Dawson, G.M.B. Parkes, P.A. Barnes, G. Bond, R. Mao, Carbon 46 (2008) 220228.

[46] A. Domínguez, B. Fidalgo, Y. Fernández, J.J. Pis, J.A. Menéndez, Int. J. Hydrog. Energy 32 (2007) 4792-4799.

[47] T.P. Wampler, Applied Pyrolysis Handbook, CRC Press, New York, 1995.

[48] M. Seeger, R.J. Gritter, Journal of Polymer Science: Polymer Chemistry Edition 15 (1977) 1393-1402.

[49] R.W.J. Westerhout, J. Waanders, J.A.M. Kuipers, W.P.M. van Swaaij, Industrial \& Engineering Chemistry Research 37 (1998) 2293-2300.

[50] J.A. Onwudili, N. Insura, P.T. Williams, J. Anal. Appl. Pyrolysis 86 (2009) 293-303.

[51] D.B. Miller, I\&EC Product Research and Development 2 (1963) 220-223.

[52] S. Boxiong, W. Chunfei, G. Binbin, W. Rui, Liangcai, Applied Catalysis B: Environmental 73 (2007) 150-157.

[53] C. Wu, P.T. Williams, Applied Catalysis B: Environmental 96 (2010) 198-207. 


\section{Catalytic microwave pyrolysis of waste engine oil using} metallic pyrolysis char

${ }^{a}$ Eastern Corridor Renewable Energy Group (ECRE), School of Ocean Engineering, 987 University Malaysia Terengganu, 21030 Kuala Terengganu, Terengganu, Malaysia

$988{ }^{b}$ Faculty of Chemical and Natural Resources Engineering, University Malaysia Pahang, 989 Lebuhraya Tun Razak, 26300 Gambang, Kuantan, Pahang, Malaysia

$990{ }^{c}$ Department of Chemical Engineering and Biotechnology, University of Cambridge, 991 New Museums Site, Pembroke Street, Cambridge CB2 3RA, United Kingdom

992 lam@umt.edu.my, lrklrk1991@gmail.com, chinkui@ump.edu.my,hac1000@cam.ac.uk $993 *$ Corresponding author. Tel: +609 6683844; fax: +609 6683991; E-mail address: 994 lam@umt.edu.my, sushiung@gmail.com (S.S. Lam); Postal address: Eastern Corridor 995 Renewable Energy Group (ECRE), School of Ocean Engineering, University Malaysia 996 Terengganu, 21030 Kuala Terengganu, Terengganu, Malaysia. 
999 The temperature of the carbon bed in the system was monitored using a thermocouple that

1000 was ducted into the middle layer of the carbon bed through the center of the shaft that 1001 protrudes from the bottom of the stainless steel stirrer shaft. The thermocouple probe is in 1002 direct contact with both the samples and the carbon in the reactor during experiment, and the 1003 temperature measured is logged for subsequent analysis. In addition, ferrite core 1004 thermocouple connectors and cable clamps were used to reduce the electromagnetic 1005 interference caused by the microwaves on the temperature measurement.

1006 Accurate measurement of the evolution of the temperature of the carbon bed was difficult 1007 during the heating process - firstly, there are inherent difficulties involved in measuring this 1008 parameter in microwave devices [1]; secondly, it should be noted that the temperature is not 1009 uniform throughout the carbon bed during the initial heating to the target temperature; electrical arcing was found to occur for a relatively short period at the beginning of the 1011 heating process, but it stopped when the carbon bed had been heated to the target 1012 temperature. A stirred bed reactor is used in this study in which the physical movement and mixing of carbon particles by the stirring system creates a uniform temperature distribution,

1014 independent of the penetration depth of the microwaves into the bed of particulate-carbon.

1015 Provided the temperature is kept consistent and uniform in this system, once the thermal 1016 equilibration and steady state temperature were reached, the temperature shown by the 1017 thermocouples are assumed to give a reliable reading of the average temperature of the bulk 1018 carbon bed.

1019 [1] Menéndez JA, Menéndez EM, Garcia A, Parra JB, Pis JJ. Thermal treatment of active 1020 carbons: a comparison between microwave and electrical heating. J Microwave Power EE 1021 1999;34:137-43. 


\section{Appendix B. Elemental analysis}

1025 Samples were analyzed on a dry or moisture-free basis by pre-heating at $200^{\circ} \mathrm{C}$ to remove 1026 any moisture (residual water) and other remaining low boiling point compounds. They were 1027 then burned at $1000^{\circ} \mathrm{C}$ in a flowing stream of oxygen. The products of combustion $\left(\mathrm{CO}_{2}\right.$, $1028 \mathrm{H}_{2} \mathrm{O}, \mathrm{N}_{2}$ and $\mathrm{SO}_{2}$ ) then passed through the system with $\mathrm{He}$ as the carrier gas, and their content 1029 of carbon, hydrogen, and sulphur were measured quantitatively by selective IR absorption 1030 detectors, except for the nitrogen, which was measured by a thermal conductivity detector. 1031 Oxygen content was measured by pyrolyzing a separate sample at $1300^{\circ} \mathrm{C}$ in a VTF-900 1032 pyrolysis furnace (LECO Corporation, Michigan, USA). The oxygen released in the pyrolysis reaction then reacted with activated charcoal to form $\mathrm{CO}$, which was converted to $\mathrm{CO}_{2}$ by

1034 passing through an oxidation tube with $\mathrm{He}$ as the carrier gas. The $\mathrm{CO}_{2}$ generated was then 1035 measured as above by an IR detector.

1036

1037

\section{Appendix C. Thermogravimetric analysis}

1038 The sample ( $20 \mathrm{mg})$ was heated from ambient temperature to $600{ }^{\circ} \mathrm{C}$ at a heating rate of $103925^{\circ} \mathrm{C} / \mathrm{min}$ with high purity $\mathrm{N}_{2}$ as the carrier gas, which then switched to $\mathrm{O}_{2}$ gas and the 1040 thermo balance was ramped to $950{ }^{\circ} \mathrm{C}$ with a final holding time of $20 \mathrm{~min}$; the carrier gases 1041 were vented through the apparatus at a flow rate of $0.1 \mathrm{~L} / \mathrm{min}$. The fraction decomposed 1042 between 100 and $600{ }^{\circ} \mathrm{C}$ refers to the volatile matter content of the sample, and fixed carbon 1043 refers to the fraction between 600 and $900{ }^{\circ} \mathrm{C}$, and the fraction above $900{ }^{\circ} \mathrm{C}$ refers to the ash 1044 content of the sample. 